BIBLIOTECA

INSTITUTO DE QUIMICA

Universidado de São Paulo

$$
\text { t: } 19.597
$$

Universidade de São Paulo

Instituto de Química

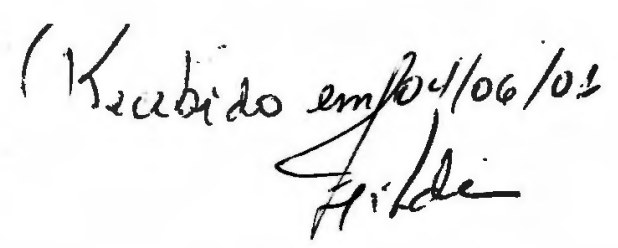

NÁO LiCACS

241838

\title{
ESTUDO COMPUTACIONAL DE CETONAS DE COOKSON E DERIVADOS
}

Sergio Augusto Jardino Filho

Dissertação de Mestrado

Prof. Dr. João Pedro Simon Farah

orientador

São Paulo

2001 
DEDALUS - Acervo - CQ

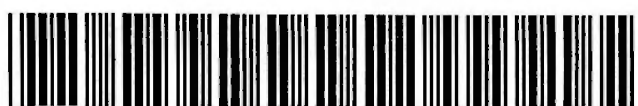

30100003816

Ficha Catalográfica

Elaborada pela Divisão de Biblioteca e

Documentação do Conjunto das Químicas da USP.

J37e

Jardino Filho, Sergio Augusto

Estudo computacional de cetonas de Cookson e derivados / Sergio Augusto Jardino Filho. -- São Paulo, 2001.

$60 \mathrm{p}$.

Dissertação (mestrado) - Instituto de Química da Universidade de São Paulo. Departamento de Química Fundamental.

Orientador: Farah, João Pedro Simon

1. Química quântica 2. Computação aplicada à Química 3. Cetona : Química orgânica I. T. II. Farah, João Pedro Simon, orientador. 


\section{"Estudo Computacional de Cetonas de Cookson e Derioados".}

\section{SÉRGIO AUGUSTO JARDINO FILHO}

DISSERTAÇĀO DE MESTRADO SUBMETIDA AO INSTITUTO DE QUíMICA DA UNIVERSIDADE DE SÃO PAULO COMO PARTE DOS REQUISTIOS NECESSÁRIOS Ã OBTENÇÃO DO GRAU DE MESTRE EM CIÊNCIAS - ÁREA: FísICO-QUÚMICA

Aprovada por:

Prof. Dr. JOÃO PEDRO SIMON FARAH

(Orientador e Presidente)

\begin{tabular}{l}
\hline Prof. Dr. MICHEL LOOS \\
IQ - USP \\
\hline
\end{tabular}

Prof. Dr. ROY EDWARD BRUNS

IQ - UNICAMP 


\section{Agradecimentos}

Este trabalho não teria sido possível sem a ajuda de algumas pessoas, às quais eu devo a minha gratidão. Devo os meus agradecimentos ao Prof. Farah pela flexibilidade e pelo rigor com que orientou o trabalho e ao Prof. Ivan Campos pelas discussões. Devo os meus agradecimentos aos amigos do laboratório; à Karina, que foi sempre muito prestativa e atenciosa, e ao Augusto, pelas discussões e pela leitura de parte da dissertação durante a sua elaboração. Devo agradecimentos aos amigos Nalvo, Luís Gustavo e William, por dedicarem parte do seu tempo a ler e discutir a versão provisoria do trabalho. Devo agradecimentos aos funcionários do $\mathrm{CCE}$, em especial à Rosa Perez e ao. Francisco Ribacionca pela acessoria prestada ao trabalho computacional. Devo agradecer ainda à minha namorada Mirian pelos conselhos sobre a escrita do texto.

Gostaria de agradecer ainda à Gerência de Tintas e Vernizes Automotivos da BASF SA, que permitiu que eu me ausentasse muitas vezes durante o período em que trabalhei para ela, para dedicar-me a esta dissertação; ao CNPq, pela bolsa concedida durante o primeiro ano deste trabalho e aos

funcionários do Instituto de Química, sobretudo os da Pós-graduação e da Biblioteca. A todos os demais que foram por mim esquecidos, ficam as minhas desculpas e os mais sinceros agradecimentos. 


\section{Resumo}

Neste trabalho foram estudadas as moléculas conhecidas como cetonas-gaiola de Cookson e seus derivados pelo uso de técnicas computacionais de modelagem molecular. Estas moléculas participam de cicloadições [2+2], uma classe de reações cujo mecanismo ainda é estudado. As técnicas usadas foram as do Conjunto Completo de Funções de Base (CBS-4), Hartree-Fock, métodos de Teoria do Funcional de Densidade pBP e B3LYP e semi-empírico PM3.

As técnicas foram usadas com diferentes conjuntos de base para analisar as conformações das moléculas e avaliar a exatidão do método em reproduzir resultados experimentais de termodinâmica $\mathrm{e}$ ressonância magnética nuclear. Com base na concordância dos resultados e com as caraterísticas do método, procura-se inferir quais as características estruturais e interações atômicas que explicam os resultados experimentais e os calculados. Foi estudada também a solvatação das espécies.

Os programas empregados foram o Gaussian 94, Spartan 5.0, MOPAC e Amsol 6.6. Os resultados mostraram as interações interatômicas mais relevantes para a determinação das estabilidades relativas das moléculas. Foi considerado o efeito da estrutura no resultado de cálculos de energias e avaliado o método de reações isodésmicas para moléculas de estrutura complexa.

\footnotetext{
Abstract

In this work the molecules known as Cookson's cage ketones and similar adducts were studied with the use of computational molecular modelling techniques. These molecules participate in cycloadditions [2+2], a class of reactions whose mechanism is still being studied. The techniques used were the Complete Basis Set (CBS-4), Hartree-Fock, Density Functional Theory methods pBP and B3LYP and semi-emprical PM3.

The techniques were used with some basis sets to analise the molecular conformations and evaluate the agreement of the calculated with the experimental results of thermodynamics and NMR spectroscopy. Based on the agreement between the results and on the characteristics of the methods, it is sought to determine the structural characteristics and atomic interactions that explain the results. The solvation of the species was also studied.

The programs used were the Gaussian 94, Spartan 5.0, MOPAC and Amsol 6.6. The results show the more important interactions that determine the relative stabilities of the molecules. The effect of the molecular structure on the energy calculation was studied and the method of isodesmic reactions was evaluated for complex molecules.
} 


\section{Sumário}

I. Introdução

1

i. Compostos gaiola

ii. Cetonas de Cookson

iii. Reações pericíclicas

II. Objetivo

III. Recursos

IV. Métodos de cálculo

i. Introdução

ii. Métodos e bases

iii. Métodos de Hartree-Fock e Møller-Plesset

iv. Método do Conjunto Completo de Funções de Base

v. Teoria do Funcional de Densidade

vi. Métodos semi-empíricos

vii. Modelos de solvatação

V. Resultados e discussão

i. Análise conformacional

25

ii. Calores de isomerização

iii.Calores de combustão

iv. Cálculos de deslocamentos químicos de RMN

v. Outros resultados da literatura

vi. Fase condensada

VI. Conclusão

VII. Referências Bibliográficas 


\section{Introdução}

\section{i. Compostos gaiola}

Compostos policíclicos conhecidos como "compostos-gaiola" são substâncias que chamam a atenção pela forma incomum que possuem. Como exemplos conhecidos, podem ser citados o cubano [Eaton e Cole, 1964] e o fulereno [Kroto et al., 1985] (Figura 1).

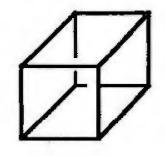

Cubano

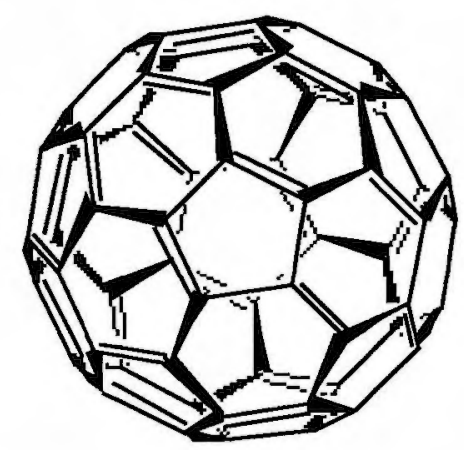

Fulereno

Figura 1. Estruturas do cubano e do fulereno.

Muitas outras moléculas podem ser formadas, como por exemplo derivados do cubano [Griffin e Marchand, 1989] e dodecahedranos [Paquette, 1989].

O nome compostos gaiola sugere que uma aplicação possível para estas estruturas seria a de aprisionar moléculas ou átomos no interior das suas cavidades. A inserção de espécies químicas no interior de cavidades pode ser interessante para proteger a substância inserida de meios agressivos, solubilizá-la num meio no qual ela é insolúvel ou estudar interações entre átomos não ligados da gaiola e da espécie introduzida. Motiva o estudo de estruturas-gaiola também a sua forma, cuja estética desperta a curiosidade em conhecer as suas propriedades. A dificuldade em sintetizar tais estruturas é também uma motivação ao seu estudo, pois suas estruturas complexas representam um desafio.

Se existem anéis pequenos de três ou quatro carbonos na estrutura, o seu efeito no comportamento químico e nos mecanismos de reação pode ser estudado. A existência de grupos funcionais em posições proximas permite a investigação da interação entre eles, o que é evitado em moléculas mais flexíveis.

Compostos policíclicos e intermediários sintéticos importantes, como na preparação de substâncias de ocorrência natural, como triquinanas [Mehta et al., 1983], hirsutenos [Mehta et al., 1981], e precapneladieno [Mehta e Murthy, 1984].

Moléculas-gaiola possuem muitas aplicações possíveis [Marchand, 1995], e como são estruturas 
grandes, que podem conter muitos grupos funcionais, a possibilidade de uma reação intramolecular também pode ter aplicações interessantes, como no caso das cetonas de Cookson (Equação 1).
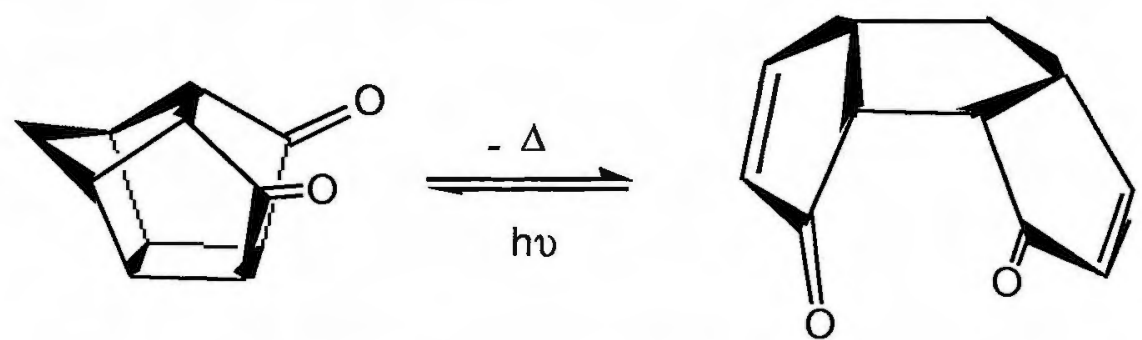

(Equação 1)

A equação 1 é uma adição [2+2] reversível facilmente observada na presença de ácidos de Lewis [Okamoto et al., 1985], e por isso foi sugerida a sua aplicação em conversores térmicos de energia solar [Mehta et al., 1979 e 1984]. Como o produto formado pela fotociclização libera calor ao regenerar a molécula insaturada, a sua utilização seria, de acordo com os esquemas de aproveitamento de energia solar [Sharf et al. 1979], viável. Outro exemplo de adição [2+2] com potencial aplicação em armazenagem de energia solar é o par norbornadieno-quadriciclano [Ristic et al., 1992] (Equação 2).
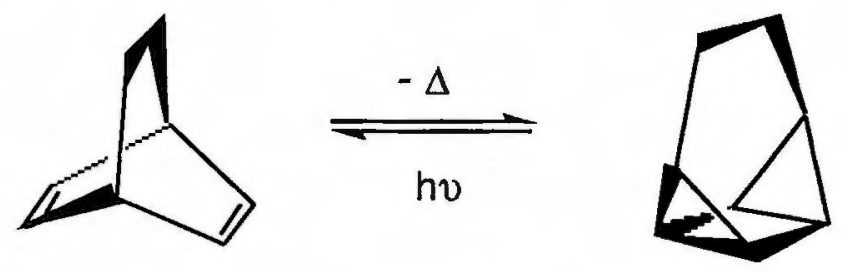

(Equação 2) 


\section{ii. Cetonas de Cookson}

Cetonas de Cookson são moléculas policíclicas na forma de gaiola (Figura 2).

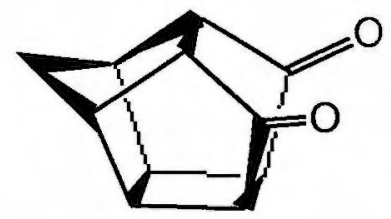

$\mathrm{S} 12$

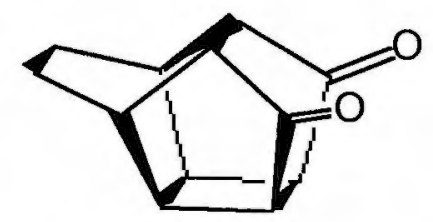

S22

Figura 2. Cetonas-gaiola de Cookson.

S12: Pentaciclo[5.4. $\left.0^{2,6} \cdot 0^{3,10} \cdot 0^{5,9}\right]$-undecano-8,11-diona ou PCUD.

S22: Pentaciclo[6.4. $\left.0^{2,7} \cdot 0^{3,11} \cdot 0^{6,10}\right]$-dodecano-9,12-diona.

As cetonas de Cookson são obtidas por uma fotocilização [2+2]. Os números entre colchetes indicam o número de elétrons cedidos pelos reagentes para a reação (Equações 3 e 4).

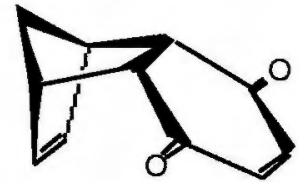

S11

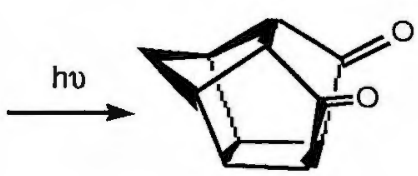

S12

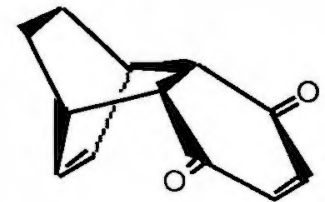

S21

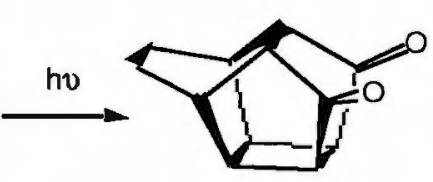

$\mathrm{S} 22$
(Equação 3)

(Equação 4)

A síntese da substância S11 (Triciclo[8.1 $\left.1^{5,8} \cdot 0^{4 a, 8 a}\right]-2,6$-undeceno-1,4-diona) foi obtida pela primeira vez pela reação de Diels-Alder do ciclopentadieno com a enediona conhecida como p-benzoquinona em meio alcoólico [Albrecht , 1906] (Equação 5).

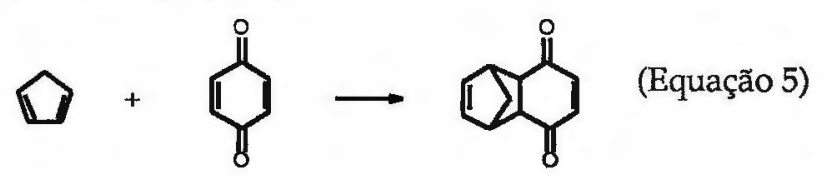

Entretanto, a estrutura admitida como correta foi determinada em dois trabalhos publicados cerca de 20 anos após a publicação do trabalho de Albrecht [Diels et al., 1925 e 1928]. Na mesma época foi publicada a descoberta da foto-sensibilidade dos cristais do aduto formado [Diels e Alder, 1929], mas sem esclarecimento da estrutura dos produtos obtidos.

A estereoquímica das espécies das reações acima foi estudada e determinada bastante tempo 
depois da descoberta das substâncias e de algumas de suas propriedades. A estrutura da molécula S11 foi determinada cerca de 20 anos após os trabalhos iniciais [Alder e Stein, 1953], e a proposição da estereoquímica para $S 12$ foi feita apenas em 1958 [Cookson et al., 1958]. O mesmo autor estudou as conformações de enedionas e determinou a sua estabilidade relativa pela redução das mesmas com hidrogênio catalisada com platina em meio de acetato de etila [Cookson et al., 1963], e estudou as propriedades espectroscópicas e termodinâmicas dos compostos anteriormente descobertos, além de ter encontrado que o isômero exo é o mais estável, apesar do isômero endo ser o formado [Cookson et al., 1963] (Figura 3).
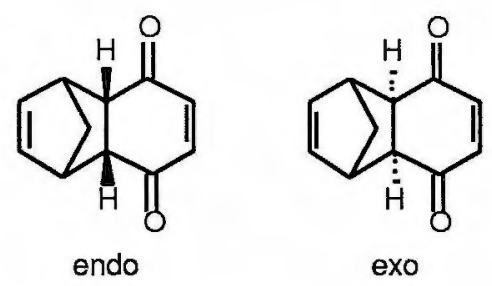

Figura 3. Isômeros endo e exo para o aduto de ciclopentadieno e benzoquinona.

Uma incerteza na estrutura das moléculas acima é a conformação do anel enediônico oriundo da p-benzoquinona. Baseado em dados de RMN, sustenta-se que o anel enediônico tem uma conformação planar [Bruce, 1985], pois esta maximiza a conjugação dos orbitais p dos carbonos carbonílicos e dos olefínicos e minimiza a repulsão eletrônica entre as carbonilas. Entretanto, em estudos anteriores [Le Fèvre, 1935 e Arbuzov, 1976], propôs-se uma estrutura onde o anel encontra-se com os planos das carbonilas inclinados, o que deixa o anel numa conformação do tipo barco.

Um outro aspecto interessante das moléculas participantes das equações 3 e 4 , é o fato das molécưlas-gaiola serem mais estáveis que as moléculas abertas. Isto foi observado pela exotermicidade dos calores de reação das equações 3 e 4, obtidos pela determinação dos calores de combustão dos reagentes e produtos[Cookson, 1964]. Os calores de combustão são confiáveis, pois uma determinação recente de calor de combustão da molécula S12 apresentou um valor totalmente concordante [Jimenez et al., 1999]. 


\section{iii. Reações pericíclicas}

Como mencionado no ítem anterior, a formação de cetonas de Cookson se processa via uma adição [2+2]. Este tipo de reação pertence à classe das reações pericíclicas [Woodward e Hoffman, 1969], cuja definição é a de uma reação na qual o rearranjo concertado das ligações químicas ocorre através de um arranjo cíclico de átomos ligados [Comission on Physical Organic Chemistry (IUPAC), 1994]. Para o caso da adição [2+2], pode-se imaginar que o estado de transição seja um quadrilátero, e que no caso de uma adição [4+2] o estado de transição tenha a forma de um hexágono. O reagente e o produto de uma reação pericíclica são chamados isômeros de valência.

A primeira tentativa de explicar o mecanismo de uma reação pericíclica, foi o de um estado de transição aromático baseado na estrutura do benzeno, para uma adição [4+2] entre butaditeno e eteno [Evans, 1938 e 1939]. Nesse trabalho foi calculada a energia de ativação pelo cruzamento das curvas de atomização dos reagentes e dos produtos. Este modelo permaneceu aceito até a publicação do modelo de Woodward-Hoffmann [Woodward e Hoffmann, 1969], onde a simetria e a interação de orbitais é usada para explicar não somente o mecanismo de uma adição [4+2], mas de todas as adições pericíclicas nas quais é formado um ciclo a partir de moléculas insaturadas alifáticas. Neste trabalho o termo adição pericíclica foi proposto. Com argumentos de simetria foram propostas regras de seleção usadas para prever se uma reação pericíclica ocorrerá ou não em determinadas condições experimentais, como aquecimento $\mathrm{e}$ incidência de luz. Pelas regras, se os reagentes contarem com ( $4 n+2)$ ou com 4 n elétrons $\pi$, de acordo com o sentido da rotação dos orbitais que formam as ligações, a reação será permitida ou proibida de acordo com as condições experimentais. As condições experimentais consideradas são a presença ou ausência de luz ou calor. O modelo é complementado pelo modelo de orbitais de fronteira [Fleming, 1976], que define a interação do orbital ocupado de maior energia (HOMO) com o orbital vazio de menor energia (LUMO), como necessária à ocorrência de reações como as pericíclicas.

Usos de reações de adição [2+2] foram investigados na época da sua descoberta. Foram empregadas, por exemplo, na síntese da cânfora de carvona (Equação 6) [Büchi, 1957] e na isomerização da eucarvona (Equação 7) [Büchi, 1960]. 


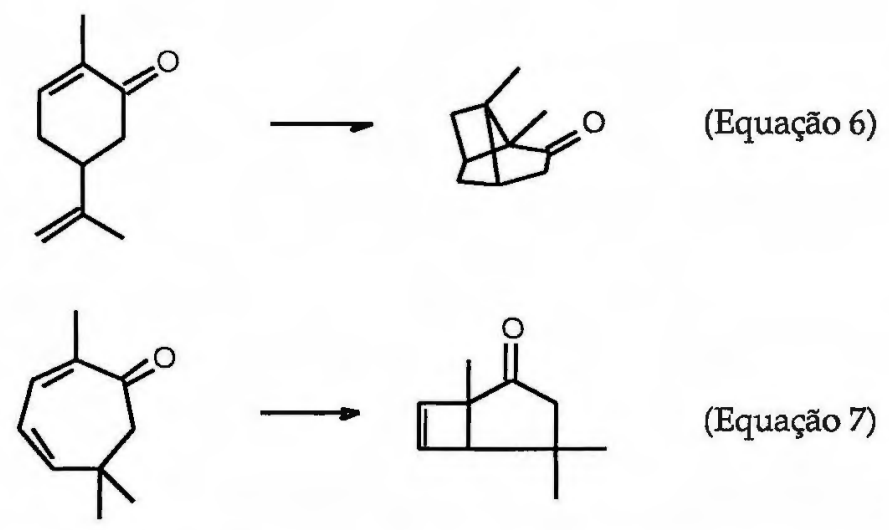

O mecanismo de adições [2+2] como as mostradas é um assunto bastante estudado, e existem algumas hipóteses para explicá-lo. A existência de uma espécie birradicalar intermediária foi proposta baseada nos estudos das adições [2+2] feitos na primeira metade da década de 1960 [Dilling, 1966]. Um exemplo de um birradical deste tipo pode ser imaginado como o mostrado na Figura 4.

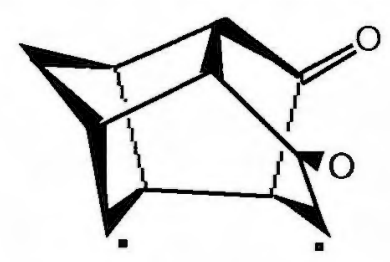

Figura 4. Espécie birradicalar intermediária para a formação de uma cetona de Cookson.

Foi proposta a existência de estados tripletes em reações intermoleculares de adição de um derivado do aduto de ciclopentadieno e p-benzoquinona a olefinas e alcinos [Barltrop, 1969], (Equação 8).

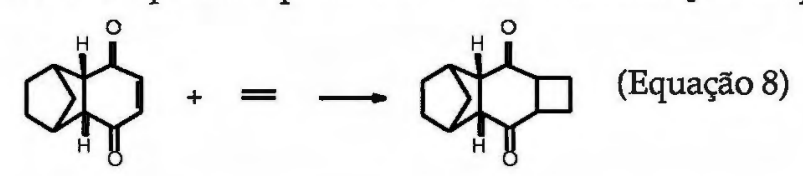

O estudo prático de rendimento quântico destes compostos numa matriz sólida de sílica-gel [Lazare,1981] revelou que as moléculas não são estáveis sobre este material e enolizam-se, exceto se forem introduzidas metilas nas posiçóes 3 e 8 a (Figura 5). No mesmo trabalho apresentam-se resultados que indicam que a mudança da polaridade do solvente não afeta o rendimento quântico do sistema. 


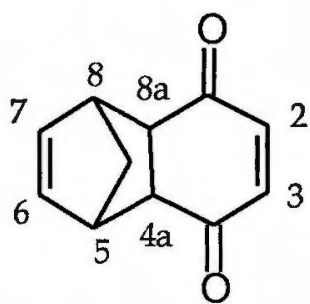

Figura 5. Numeração do aduto de ciclopentadieno e benzoquinona.

As regras criadas a partir do modelo de Woodward-Hoffmann são bem sucedidas na previsão da ocorrência de uma reação pericíclica, mas não explicam qual é a estrutura do estado de transição. Numa reação pericíclica formam-se mais de uma ligação química, o que resulta num ciclo de átomos ligados; porém, o modelo não diz se estas ligaç̃es formam-se ao mesmo tempo ou não. Diz-se apenas que se não houver nenhuma interferência, este estado será concertado com formação síncrona das ligações.

Este modelo não inclui a possibilidade da existência de um intermediário de reação. Se há um intermediário de reação, este poderia ser um birradical ou um zwitterion. As adições com a formação do zwitteríon são chamadas polares, e as concertadas ou intermediadas por um birradical, apolares. Numa interpretação da teoria de Woodward-Hoffmann que admite a existência de intermediários de reação [Houk et al., 1995], afirma-se que nas reações proibidas pelas regras, formam-se intermediários de reação. Existem quatro possibilidades para o intermediário de reação e para o estado de transição de uma adição pericíclica [2+2] (Figura 6).

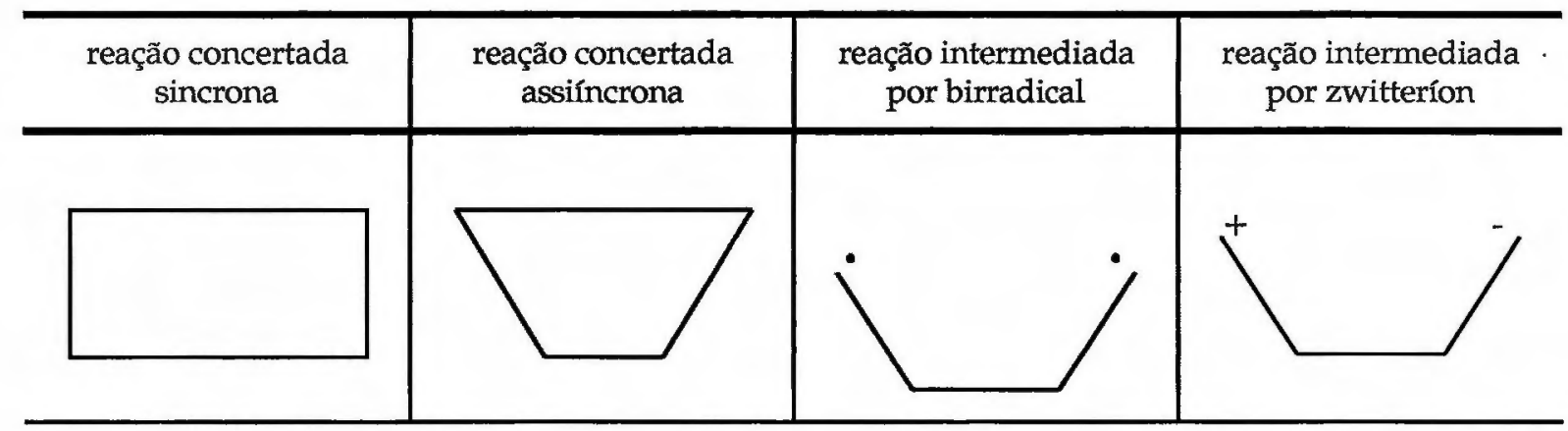

Figura 6. Estados de transição e intermediários possíveis para um adição pericíclica [2+2] qualquer. Estão representados apenas os quatro átomos que participam da formação do ciclo.

Por argumentos de simetria e cálculos semi-empíricos, afirmou-se que não há razão alguma para que o estado de transição de uma transformação pericíclica seja simétrico, isto é, que ela tenha um mecanimo concertado e síncrono [McIver, 1974]. De acordo com o modelo termodinâmico de coordenada de 
reação, reações concertadas síncronas são improváveis pois a sua energia de ativação deve ser a soma da energia de ativação da quebra das duas ligações necessárias para que ela ocorra [Evans e Polanyi, 1938]. Assim, um mecanismo com a formação assíncrona das ligações deve ser menos energético e mais provável [Dewar, 1984]. A afirmação de Dewar da impossibilidade da reação concertada síncrona causa controvérsia desde a época em que foi publicada [Maugh, 1984]. Uma explicação para o mecanismo com estado de transição síncrono numa reação [4+2] sem uma energia de ativação muito elevada é a conjugação das ligações duplas, que reduziria a energia da quebra simultânea das duas ligações [Houk, 1995].

Estas teorias são testadas experimentalmente, paralelamente ao seu desenvolvimento conceitual. A hipótese da existência de intermediários foi admitida ao observar-se a formação de tripletes numa adição [2+2], o que é um indício da existência de um birradical [Jones,1976]. A influência do solvente na velocidade de adiçőes [2+2] entre tetracianoetenos e ésteres de enóis é um outro indício da existência de intermediários de reação, mas neste caso a formação de um zwitteríon é o que explica a mudança na velocidade da reação ao mudar a polaridade do meio [Huisgen, 1980] . Neste mesmo trabalho é estudada a cicloadição entre $\mathrm{N}$-metil-C-fenil initrona e acrilato de etila (Equação 9), em que o solvente tem pequena influência na cinética do processo, o que foi explicado pela assincronia na formação das ligações num estado de transição concertado. Este é mais um indicador que as reações pericíclicas admitem outros estados de transição que não sejam simétricos..

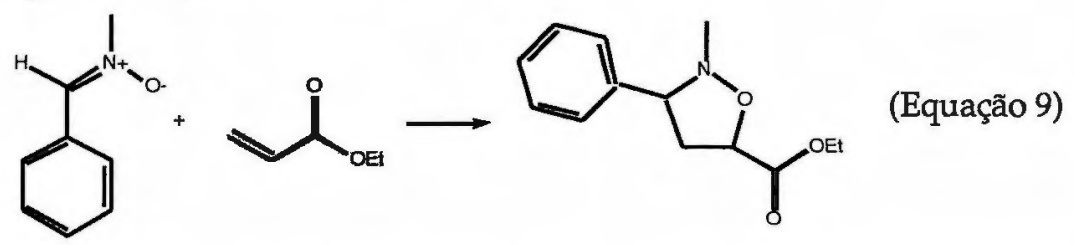

Cálculos ab initio [Burke, 1979] e semi-empíricos [Dewar, 1974] mostram que birradicais devem ser favorecidos em detrimento de espécies com separação de carga. Outros estudos semi-empíricos prevêem intermediários zwitteriônicos [Jug, 1979 e Durán, 1982]. Em tais estudos não foram incluídos efeitos de solvatação para a determinação das estruturas. Considerando o solvente, encontrou-se um mecanismo com um intermediário birradicalar para a adição [2+2] entre álcool vinílico e tetracianoetileno [Essefar, 1988]. A hipótese birradicalar foi estudada experimentalmente pela reação de derivados do N-benzoilindol e ciclopenteno ou ciclohexeno [Hastings e Weedon, 1991] (Equação 10).

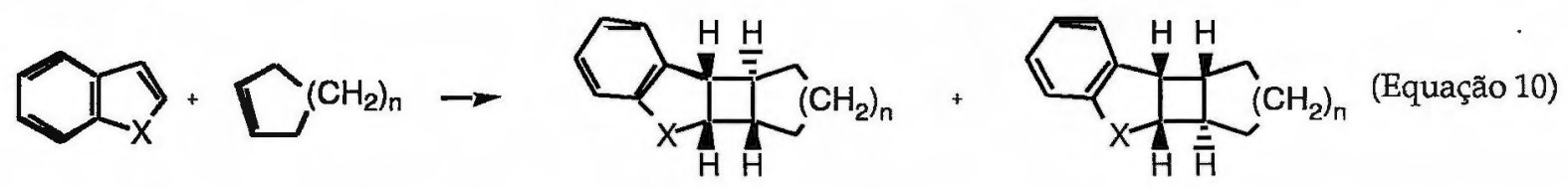

Como foram encontrados os dois isômeros geométricos mostrados na equação 10, supôs-se que num mecanismo concertado não há tempo para alteração da estereoquímica, e por isso a detecção de dois isômeros é um indicativo da existência de um intermediário. Este intermediário teria tempo de vida suficiente para a isomerização, o que não seria possível num mecanismo concertado. A hipótese birradicalar 
também foi testada para a formação do ciclobutano a partir da dimerização do eteno em fase gasosa num laser de femtosegundos acoplado a um espectrômetro de massa [Zewail et al., 1994]. Este resultado indica que o birradical deve existir como um intermediário para esta reação, que é a adição [2+2] mais simples.

Reações pericíclicas foram estudadas computacionalmente em sistemas que contém outras funções orgânicas. A reação entre olefinas substituídas e isocianatos também substituídos (Equação 11) foi estudada por cálculos ab initio HF e MP em diferentes bases para otimizar geometrias e calcular energias, e o método SCRF para estudos de solvatação [Cossío, 1995]. As suas conclusões foram que o mecanismo da reação é concertado, e que certos substituintes aceleram o processo sem alterar o mecanismo.. A solvatação teria um efeito de tornar o mecanismo assíncrono até o ponto de incluir duas etapas, ou seja, a formação de um intermediário.

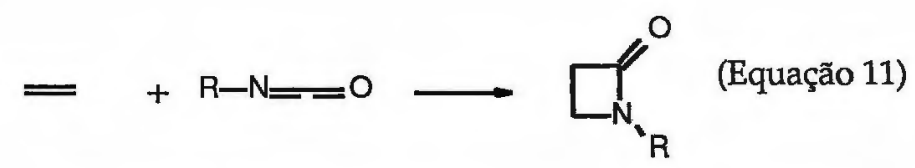

Se, ao invés de um isocianato, o reagente for um ceteno (Equação 12), como estudado com o método CAS-MCSCF/STO-3G, o mecanismo não será concertado, mas intermediado por um birradical [Rzepa et al., 1993]. Neste trabalho, a convergência dos cálculos indica que o uso de modelos de solvatação de cavidade elipsoidal não é adequado para a modelagem deste sistema.

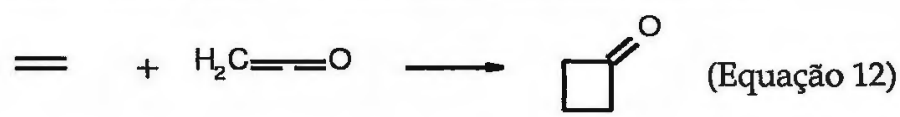

O efeito do solvente no mecanismo da reação correlata entre cetenos e iminas (Equação 13) fói estudada por MP2/6-31G* [Ruiz-López, 1993] e por MP2 e MP4 combinados com GCOSMO, que é um dielétrico contínuo para o estudo da solvatação [Truong, 1998]. Afirma-se que o mecanismo de reação deve conter um intermediário quando em solução, e em fase gasosa o mecanismo é concertado.

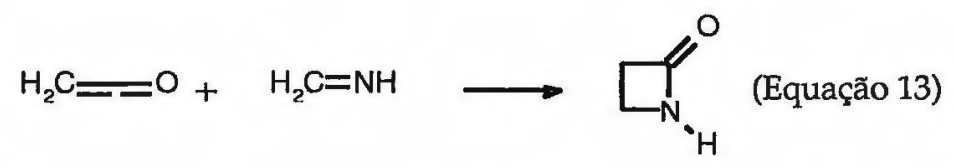

Nestes trabalhos nota-se que este tipo de reação pode ser muito influenciada pelo solvente, e que o mecanismo da reação deve se diferenciar, se as espécies estão em solução ou em fase gasosa. Resultados que, por cálculo computacional, confirmam as hipóteses da mudança de mecanismo e da existência de birradicais em solução com o uso de diferentes técnicas em vários sistemas foram publicados e são pontos favoráveis à hipótese intermediada do mecanismo das adições pericíclicas. Como exemplo pode ser citado um trabalho feito com o método multiconfiguracional MC-SCF/4-31G aplicado ao estudo de adições em fase condensada [Bernardi, 1995], que indica que o mecanismo concertado é improvávél tanto para cicloadições polares quanto para apolares. Propõe-se um estado de transição na posição gauche, onde o zwitteríon e o birradical poderiam ser favorecidos para as adições polares e apolares, respectivamente. 
Uma alternativa para simular a solvatação é o uso do Método de Monte Carlo(MC). Este método foi empregado no estudo da reação entre metilvinil-éter e 1,1-dicianoetileno(DCNE) [Jorgensen, 1996]. Energias obtidas por MP2/6-31G*//B3LYP/6-31G* apontam para uma mudança de mecanismo, quando se passa da fase gasosa, onde o mecanismo é concertado, para a condensada, onde tanto o estado de transição quanto o intermediário são zwitteríons.

Já existe uma quantidade razoável de trabalhos na literatura com outros estudos computacionais de reações pericíclicas, e como exemplo podem ser citados trabalhos em que foram estudadas a dimerização do butadieno, em que observa-se a possibilidade de existência do birradical [Rzepa et al., 1991]; estudaram-se também algumas reações pericíclicas [4+2] e [2+2], considerados casos concertados síncrono e assíncrono e também o caso do birradical [Houk et al., 1994]. O método foi o CASSCF nas bases 3-21G e 6$31 G^{*}$, e foi obervada a boa concordância do método com resultados experimentais. $\mathrm{O}$ caráter aromático das cicloadições foi discutido pelo cálculo de energia de aromatização de estados de transição de reaçōes [2+2] e [4+2] [Bernardi et al., 1995]. A conclusão é que o estado de transição de seis membros é muito mais estabilizado que o de quatro membros, o que está em concordância com noções intuitivas de química, onde estruturas análogas ao benzeno têm caráter aromático.

Mesmo com estes resultados favoráveis ao modelo não concertado e assimétrico, o modelo concertado simétrico é admitido para muitos casos, como as reações Diels-Alder de triazolinadionas com olefinas (Equação 14). Estas reações admitem tanto o mecanismo concertado quanto o intermediado, dependendo da olefina usada [Houk et al., 1998].

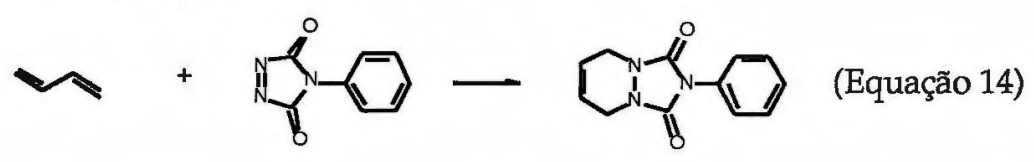

A isomerizaçãodo ciclooctatetraeno (Equação 15), estudada por métodos semi-empírico, ab initio e funcional de densidade, apresenta características difíceis de explicar com os modelos disponíveis, pois nesta molécula ocorrem adições [2+2] intramoleculares cujos resultados indicam para um processo não radicalar governado pela simetria orbital. A presença de substituintes pode alterar o mecanismo. Neste sistema, os ciclos de quatro membros podem ser formados ao mesmo tempo, o que não é previsto pela regra, ou um ciclo de cada vez. Cada um destes mecanismos é favorecido de acordo com substituintes inseridos no ciclooctatetraeno, o que também não é considerado pelas regras de Woodward-Hoffamann [Rzepa et al., 1998].

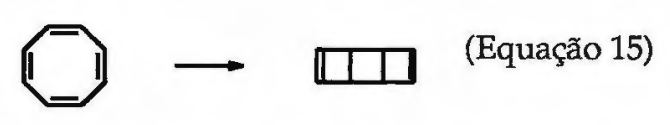

Adições [4+2], ou reações de Diels-Alder, são um assunto correlato bastante estudado, e o seu estudo apresenta dificuldades semelhantes às encontradas na investigação de sistemas [2+2]. As regras de Woodward-Hoffman sugerem um mecanismo concertado e síncrono. Pelo estudo experimental do sistema eteno-butadieno, foi sugerido o oposto, que o mecanismo desta reação passa por um intermediário 
birradicalar assimétrico [Dewar, 1986]. Através de cálculos semi-empíricos AM1 e MNDO, e também ab inito RHF e UHF, chega-se a tal conclusão e recomenda-se a utilização do método de Hartree-Fock irrestrito (UHF) para a pesquisa de estados de transição, pois este pode assumir uma conformação assimétrica neste modelo. Estes resultados estão em concordância com um trabalho experimental complẹmentado com cálculos ab initio, onde por métodos CASSCF/3-21G e B3LYP/6-31G* estudou-se uma reação da metileno-furanona incluindo o efeito de grupos substituintes. A conclusão é que a reação atravessa um estado de transição birradicalar [Branchendell, 1977].

Por outro lado, existe a possibilidade de que os métodos de cálculo não sejam adequados, ou que determinados sistemas sejam melhor modelados por certos métodos de cálculo. Este tipo de questionamento foi levantado ao se estudar um estado de transição aromático para o sistema butadieno-eteno por CASSCF/4-31G e IRC [Karadakov, 1998]. Segundo os autores, métodos ab initio favorecem estados de transição concertados e métodos semi-empíricos privilegiam mecanismos seqüenciados. Uma possibilidade para contornar este possível defeito é o uso combinado de métodos de cálculo, como B3LYP/6-31G*// AM1 utilizado para estudar uma reação Diels-Alder concertada simétrica complexa e decidir qual o mecanismo do processo pela comparação das energias [Domingo, 1999].

Além das discussões sobre a natureza do mecanismo, discute-se a influência de outros fatores no mecanismo. Um destes fatores é a temperatura, cujo efeito no rendimento quântico de ạdições [2+2] intramoleculares em $\alpha$ - e $\beta$ - ciclohexenonas (Equação 16) é uma diminuição do rendimento quântico. Para explicar os dados, foi proposto um outro mecanismo de reação, em que a fotoexcitação produz um triplete que pode ser convertido tanto no birradical que leva aos produtos, como num outro estado triplete não birradicalar que não leva ao birradical e nem ao produto. Há cálculos semi-empíricos que sustentam a hipótese, mas sem evidência experimental [Becker, 1996].

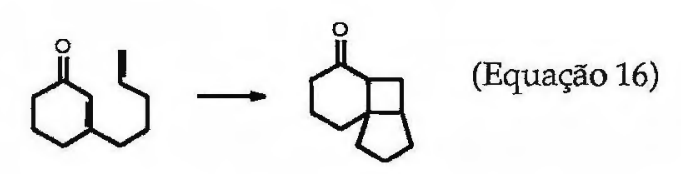

Estes trabalhos mostram o desenvolvimento do assunto, e que não há um consenso em muitos aspectos do mecanismo de reação, que possui muitas excessões para ambos os modelos considerados. 


\section{Objetivo}

Este trabalho tem por objetivo estudar por cálculos quânticos as estruturas e as energias dos compostos-gaiola conhecidos como cetonas de Cookson e dos seus derivados (Figura 7).

\begin{tabular}{|c|c|c|}
\hline código & estrutura & nomenclatura IUPAC \\
\hline S11 & & 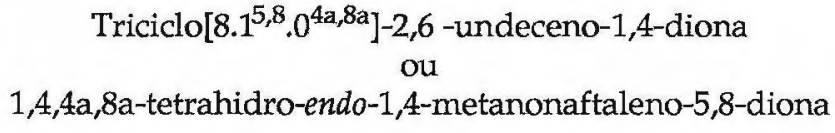 \\
\hline S12 & & Pentaciclo[5.4.0 $\left.0^{2,6} .0^{3,10} .0^{5,9}\right]$-undecano-8,11-diona \\
\hline S13 & & Triciclo $\left[6.3 .0^{8 \mathrm{a}, 9}\right]-2,5-$ undeceno-1,7-diona \\
\hline S21 & & $\begin{array}{c}\text { Triciclo }\left[8.2^{5,8} \cdot 0^{4 \mathrm{a}, 8 \mathrm{a}}\right]-2,6 \text {-dodeceno- } 1,4 \text {-diona } \\
\text { ou } \\
1,4,4 \mathrm{a}, 8 \mathrm{a} \text {-tetrahidro-endo- } 1,4 \text {-etanonaftaleno-5,8-diona }\end{array}$ \\
\hline S22 & & Pentaciclo $\left[6.4 \cdot 0^{2,7} \cdot 0^{3,11} \cdot 0^{6,10}\right]$-dodecano-9,12-diona \\
\hline S23 & & Triciclo[7.3.0 $\left.0^{8 \mathrm{a}, 10}\right]-2,6$-dodeceno-1,8-diona \\
\hline
\end{tabular}

Figura 7. Cetonas-gaiola de Cookson. Código usado neste trabalho, estrutura e nome IUPAC.

$\mathrm{Na}$ introdução foram apresentadas as principais características destes compostos e dos seus derivados. Como dito, as suas estruturas possuem algumas incertezas conformacionais, como o caso já estudado experimentalmente dos anéis enediônicos das moléculas S11 e S21 (cf. pág. 4). Além deste caso já conhecido, as conformações das demais espécies não foram tão estudadas. A conformação da molécula S22 também tem a possibilidade de uma torção na ponte de metilenos, o que cria a dúvida na simetria da molécula. As moléculas S13 e S23 também possuem possibilidades que serão aqui tratadas. 
Do ponto de vista energético, podem ser levantadas dúvidas quanto à contribuição das interaçães entre átomos não ligados e o seu efeito nas diferenças energéticas. Ou seja, a análise conformacional e a identificação das interações ajudam a compreender a estabilidade relativa das moléculas e podem ser necessárias para compreender a reatividade destes compostos. Apesar deste não ser um estudo sobre a reatividade das substâncias, a análise das interações pode ser útil na explicação das reatividades.

Todas as moléculas são policiclos, o que é um tipo de estrutura importante, dada a quantidade de compostos orgânicos policíclicos existentes. Como as moléculas escolhidas são isômeras, e as moléculasgaiola são mais "aglomeradas", pode-se avaliar o efeito da compactação dos átomos. Para fazer este tipo de avaliação, existem resultados experimentais que possibilitam o estudo por comparação [Jimenez, $1999 \mathrm{e}$ Cookson, 1964] . A estrutura compacta das moléculas-gaiola contém ainda duas carbonilas numa posição bastante interagente, o que possibilita estudar este efeito. As moléculas escolhidas são de tamanho razoável, o que permite o estudo computacional em diferentes métodos.

Os resultados deste trabalho podem ser úteis também no estudo de moléculas maiores que possuam interações semelhantes, como aglomerados de carbono, moléculas solvatadas e outros policiclos aglomerados. 


\section{Recursos}

Foram empregados os seguintes programas comerciais de modelagem molecular para otimizar e calcular a energia das estruturas: Gaussian98, Spartan 5.0, AMSOL 6.6 e MOPAC.

Com o Gaussian 98 e o com o Spartan 5.0 podem ser feitas modelagens tanto em métodos $a b$ initio como semi-empíricos. Neste trabalho eles foram usados para estudar as moléculas em fase gasosa. $\mathrm{O}$ AMSOL 6.6 é um pacote de métodos semi-empíricos voltados para o cálculo de modelos de moléculas em solvatação, e esta foi a sua utilização neste trabalho. O MOPAC foi utilizado em otimizações de geometria preliminares, antes de submeter as estruturas em métodos mais rigorosos disponíveis no Gaussian. O procedimento para utilizar estes programas está descrito clara e detalhadamente nos respectivos manuais. Como não foi feito nenhum estudo em que o código-fonte dos programas tenha sido alterado, não será feita discussão da maneira como foram submetidos os cálculos.

Os recursos computacionais mais usados para os cálculos foram os disponíveis no Laboratório de Computação Científica Avançada - LCCA - que é parte do Centro de Computação Eletrônica - CCE - desta universidade. Também foram usadas máquinas disponíveis no Instituto de Química, mas em pequena escala e normalmente apenas para utilizar o MOPAC.

No LCCA estavam à disposição máquinas de elevada capacidade de processamento, usadas por toda a comunidade de pesquisa da universidade (Figura 8)

\begin{tabular}{|c|c|c|c|}
\hline $\begin{array}{l}\text { Computador Cray } \\
\text { Cray } 990 \text { - CCE - } \\
\text { dolphin.lcca.usp.br } \\
16 \text { processadores } \\
2048 \mathrm{MB} \text { de memória } \\
55 \text { GB de área em disco } \\
2.4 \text { Gflops }\end{array}$ & $\begin{array}{l}\text { Computador IBM } \\
\text { IBM SP2 - CCE - } \\
\text { rabbit.lcca.usp.br } \\
8 \text { processadores de } 66.7 \mathrm{MHz} \\
4 \text { processadores de } 120 \mathrm{MHz} \\
4.5 \mathrm{~GB} \text { de memória } \\
109 \mathrm{~GB} \text { de área em disco } \\
3.1 \text { Gflops }\end{array}$ & $\begin{array}{l}\text { Computador Silicon Graphics } \\
\text { SGI Power Onyx2 - Infinity } \\
\text { Reality - CCE - } \\
\text { hawk.lcca.usp.br } \\
6 \text { processadores R10000 } \\
1 \text { GB de memória } \\
40 \text { GB de área em disco } \\
2.4 \text { Gflops }\end{array}$ & $\begin{array}{l}\text { Computadores Digital } \\
\text { DEC Alpha } 4100 \text { - CCE - } \\
\text { lince.lcca.usp.br } \\
\text { - leopardo.lcca.usp.br } \\
\text { - tigre.lcca.usp.br } \\
\text { - jaguar.lcca.usp.br } \\
\\
4 \text { processadores de } 466 \mathrm{MHz} \\
\text { (cada) } \\
1,5 \mathrm{~GB} \text { de memória (cada) } \\
98 \mathrm{~GB} \text { de área em disco (total) } \\
2.3 \mathrm{Gflops} \mathrm{(cada)}\end{array}$ \\
\hline
\end{tabular}

Figura 8. Recursos computacionais do LCCA/CCE utilizados no trabalho. 


\section{Métodos de cálculo}

\section{i. Introdução}

A utilização de métodos computacionais baseados na teoria quântica para estudar sistemas atômicos e moleculares avançou significativamente nos últimos anos tanto pelos progressos teóricos e nos algoritmos de cálculo como pelo aumento das capacidades de processamento e de armazenagem de dados dos computadores. Contudo, permanece uma dificuldade quanto ao seu uso como ferramenta de estudo por químicos. Isso reflete-se na dificuldade em escolher métodos adequados para estudar o sistema de interesse com os recursos computacionais disponiveis. O método mais exato é o de interação de configuração (CI), porém, dadas as limitações físicas das máquinas, só se pode utilizar este método para sistemas de poucos elétrons. Assim, de acordo com o sistema de interesse, escolhe-se um método adequado pela consideração de algumas propriedades do sistema a ser estudado. Pode-se propor um critério de escolha baseado em características como o tamanho e a quantidade dos átomos, se formam ciclos, sua carga elétrica e multipicidade de spin. Estes são exemplos de critérios a serem obsevados na escolha de um método para modelar um sistema químico, mas o método de tentativa e comparação com resultados experimentais permanece o mais indicado parâmetro de avaliação. Métodos $a b$ initio, encontram-se num estado de desenvolvimento tal que não se pode relacionar inequivocadamente métodos e sistemas [Simmons, 1991].

Um exemplo ilustrativo da dificuldade em se definir o melhor método de estudo de um sistema é dado por dois trabalhos sobre o estudo de estados de transição de reações pericíclicas. No primeiro trabalho [Wiest, 1996], o autor sugere o uso dos métodos de funcional de densidade e no segundo, sugere o uso de metodologias baseadas no método de Hartree-Fock [Wiest, 1997]. As conclusões dos trabalhos não são contraditórias, apenas mostram os aspectos favoráveis e desfavoráveis dos métodos para o estudo dos sistemas citados.

\section{ii. Métodos e bases}

O resultado de um cálculo é avaliado de acordo com dois parâmetros: o nível de teoria e o conjunto de funções de base. O nível de teoria é um parâmetro do rigor com que os cálculos são feitos. Com o método de Hartree-Fock chega-se a resultados menos precisos que com a interação de configuração, por exemplo. Ou seja, o método de interação de configuração é de um nível de teoria mais alto que o método de Hartree-Fock. Este rigor aplica-se uniformemente a todos os átomos considerados no cálculo, e se um determinado nível de teoria for aplicável a qualquer configuração de elétrons ou núcleos, ele pode ser cha- 
mado de modelo teórico.

Existem algumas exigências que precisam ser satisfeitas para que um modelo teorico seja empregável com confiabilidade. O primeiro requisito é que a função de onda e o seu autovalor sejam funções apenas da posição dos núcleos, do spin da molécula e do número de elétrons. Não admitem-se descontinuidades na hipersuperfície de potencial por causa de nenhum deslocamento atômico, nem quaisquer limitações fundadas na "intuição" química.

O modelo teórico tem como segunda exigenncia a consistência com o tamanho do sistema estudado. Ou seja, a aplicação do modelo a n moléculas idênticas infinitamente separadas não pode ter um resultado diferente caso o modelo seja aplicado a uma molécula e tenha o seu resultado multiplicado por n. Se o modelo não atende a esta exigência, não podemos aplicá-lo a moléculas de diferentes tamanhos e de alguma maneira comparar os resultados mantendo a confiança nos valores.

A última exigência é que o método seja variacional. Isso implica que a energia calculada deve ser limitada inferiormente pelo resultado da solução exata da equação de Schrödinger. Por exemplo, o resultado de uma otimização de geometria molecular por um método qualquer não pode ser de menor energia do que o previsto pela solução analítica da equação de Schrödinger independente do tempo.

As características citadas acima são desejáveis. Certos métodos podem não cumprir todas estas exigências, principalmente o caráter variacional e a consistência com o tamanho do sistema, e mesmo assim serem usados para estudar química. As cetonas de Cookson aqui estudadas são moléculas isômeras, e portanto não têm o problema de consistência de tamanho.

O segundo parâmetro de avaliação de um resultado é o conjunto de funções de base empregado. Nos métodos utiliza-se o modelo de orbitais moleculares, constituído por um somatório de funções monoeletrônicas, chamadas funções de base monoeletrônicas (Equação 17) [Hehre et al., 1986].

$$
\psi_{i}=\sum_{\mu=1}^{N} C_{i \mu} \phi_{\mu} \quad \text { (Equação 17) }
$$

N é o número de elétrons, $\psi_{\mathrm{i}}$ é o orbital molecular, $\mathrm{C}_{\mathrm{i} \mu}$ é um coeficiente de valor variạvel determinado através das iterações do algoritmo e $\phi_{\mu}$ é a função de base monoeletrônica. A função de base monoeletrônica é expandida numa série de gaussianas. Cada gaussiana chama-se primitiva, e um conjunto de gaussianas com coeficientes fixos chama-se função đe base contraída. Caso os coeficientes possam variar, a função chama-se não-contraída. Há dois tipos principais de funções usadas nos conjuntos de funções de base, as do tipo Slater (STO) e as do tipo Gaussiano (GTO). O desenvolvimento das funções foi tal que as do tipo gaussiano são as mais utilizadas [Shavitt, 1993].

Nesta dissertação utilizaram-se funções de base gaussianas de valência separada, que trata os elétrons da camada de valência de forma diferente dos das camadas internas. Estas funções de base são do tipo $n-k 1 G$ (com $n=[3,6]$ e $k=[2,3]$ ). Nestas bases cada camada interna tem $n$ primitivas e na camada de 
valência há k primitivas e uma primitiva não contraída.

Nos conjuntos de valência separada, o orbital alcança regiões mais distantes do núcleo, mas a forma com que as probabilidades distribuem-se ao redor dos núcleos não se altera. Para alterar a forma da distribuição, incluem-se funçōes de polarização. Tais funções são orbitais de forma diferente do de valência dos átomos considerados. Mais claramente, adicionam-se funções com simetria de orbitais p para átomos de hidrogênio e orbitais $\mathrm{d}$ ou $\mathrm{f}$ para átomos pesados. Este tipo de correção é particularmente importante para o caso de sistemas com distribuição assimétrica de cargas, como ligações polarizadas e anéis fortemente tensionados. Representam-se funções de polarização na nomenclatura por asteriscos do lado direito do código de gaussianas, ou seja a base $3-21 G^{*}$ adiciona funções d para não hidrogenóides. Ela poderia também ser escrita como 3-21G(d). Um conjunto maior é o $3-21 \mathrm{G}^{* *}$ ou $3-21 \mathrm{G}(\mathrm{d}, \mathrm{p})$, que adita funções $\mathrm{p}$ para átomos de hidrogênio e $\mathrm{d}$ para os demais.

Contudo, existe uma probabilidade finita de encontrar elétrons em todo o espaço ao redor do núcleo, independente da distância em que um elétron estiver, e os conjuntos de base não descrevem zonas afastadas do núcleo, que são importantes para sistemas negativamente carregados, com pares eletrônicos isolados, excitados, dentre outros. Para este tipo de estudo recorrem-se às funções difusas. Com este recursos incluem-se funções que ocupam uma região maior do espaço ao redor do núcleo com mesma simetria das funções da camada de valência do átomo. Representam-se as funções difusas com um sinal de mais precedente à letra $G$ da notação. $O$ código $3-21+G^{*}$ para representar a o conjunto polarizado em que foram adicionadas funções difusas para os átomos pesados, e também o conjunto $6-31++G^{* *}$ para simbolizar a base polarizada à qual foram adicionadas funções difusas tanto para os átmos pesados como para os hidrogênios. Nos pacotes Gaussian, existe a possibilidade da inclusão de funçбes difusas específicas para o método CBS, estas funções são chamadas difusas duplas ou simples, e são representadas por uma cruz à direita da letra $G$, como por exemplo 6-31G†.

A notação para representar estes resultados é a seguinte: escreve-se o nível de teoria à esquerda $\mathrm{e}$ separado por uma barra, a base em que o cômputo foi feito, por exemplo: HF/3-21G mostra um resultado obtido por método HF na base 3-21G. Como mencionado, é possível calcular a energia de uma geometria otimizada numa outra base e com outro modelo teórico. Nesse caso, escreve-se da seguinte maneira: o cálculo de energia do lado esquerdo, duas barras de separação e o meio de otimizar a geometria utilizado à direita; por exemplo: MP2/6-31G**//HF/3-21G onde o cálculo de energia no método $M P 2 / 6-31 G^{* *}$ foi feito sobre a geometria otimizada por HF/3-21G.

iii. Métodos de Hartree-Fock e Møller-Plesset 
O método de Hartree-Fock (HF) foi bastante utilizado neste trabalho, além de ser a base de outros métodos, por isto as suas idéias básicas serão comentadas aqui. De acordo com a equação de Schrödinger independente do tempo (Equação 18),

$$
\hat{H} \psi=E \psi
$$

o movimento dos elétrons é descrito pela função de onda $\psi$ e as energias cinética e potencial são calculadas com as informações contidas no operador hamiltoniano H. A autofunção do operador de Hartree-Fock descreve o movimento de um único elétron e é chamada orbital. É formada por duas partes, uma espacial, cujo quadrado dá a probabilidade de encontrar um elétron numa determinada região, e o spin. Por esta razão são chamadas spin-orbitais.

A função de onda total de um sistema polieletrônico deve obedecer ao Princípio de Exclusão de Pauli. Para isso, os spin-orbitais monoeletrônicos devem estar organizados de maneira tal que mantenham a propriedade de antisimetria. A expressão desta função de onda eletrônica é um produto antisimetrizado escrito na forma de um determinante conhecido como determinante de Slater. No método de HF o operador hamiltoniano é substituído por operadores monoeletrônicos conhecidos como operadores de Fock (Equação 19) [Szabo e Ostlund, 1996].

$$
f(i)=-\frac{1}{2} \nabla^{2}{ }_{i}-\sum_{a=1}^{m} \frac{Z_{a}}{r_{i a}}+v_{i}^{H F} \quad \text { (Equação 19) }
$$

Na equação acima, $f(i)$ é o operador de Fock para o i-ésimo elétron no campo de $m$ núcleos. Os dois primeiros termos do lado direito correspondem aos operadores de energia cinética e potencial dos elétrons, e $v^{H F}{ }_{i}$ é o potencial médio exercido por todos os demais elétrons e sentido no i-ésimo elétron. A equação é resolvida numericamente com o método do campo auto-consistente (SCF). O processo iterativo exige que uma função-tentativa para o spin-orbital seja usada para iniciar a computação e determinam-se os autovalores da equação de Fock. Na etapa seguinte, os resultados do potencial da etapa precedente serão usados para calcular novos autovalores, que são comparados com os resultados anteriores até que o critério de convergência seja atingido. Os n menores autovalores determinam os orbitais ocupados pelos $n$ elétrons. $O$ método usa $k$ funções de base e gera $2 k$ spin-orbitais ( $k$ orbitais de spin $\alpha$ e $k$ orbitais de spin B). Os $2 \mathrm{k}-\mathrm{n}$ demais orbitais são os virtuais ou vazios. Quanto maior for $\mathrm{k}$, maior a exatidão e menor a energia. Um número infinito de funções de base é o limite do método HF.

A deficiência do método Hartree-Fock é o tratamento da interação intereletrônica, também chamada de correlação eletrônica. O método HF considera somente a correlação média, e ignora a correlação 
instantânea. Esta deficiência é parcialmente corrigida com outros métodos.

Uma maneira de melhorar o resultado é pela consideração da influência de estados eletrônicos excitados. Por HF, constrói-se um único produto antisimetrizado de todas as combinações possíveis de spin-orbitais. Para permitir que elétrons ocupem orbitais vazios é necessário que outros determinarites sejam adicionados. $\mathrm{O}$ uso de todos os determinantes possíveis com $2 \mathrm{k}$ orbitais é chamado de Interação de Configuração (full CI). O limite do método, onde seria encontrada a solução exata, incluiria infinitos determinantes e infinitas funçōes de base, o que não é possível.

Um outro tratamento da correlação é feito através da teoria da perturbação. Nesta abordagem, o hamiltoniano aplicado à função de onda é divido em duas partes: um operador hamiltoniano comum, que pode ser o operador de Fock, e uma perturbação, cujo efeito deve ser uma pequena correção na solução encontrada com o operador não perturbado (Equação 20).

$$
\mathrm{H}=\mathrm{H}_{0}+\lambda \mathrm{H}^{\prime} \quad \text { (Equação 20) }
$$

O fator $\lambda$ dá a intensidade da perturbação representada pelo operador $\mathrm{H}^{\prime}$. A energia e a função de onda calculadas com a equação de Schrödinger para este hamiltoniano perturbado são escritas como expansões em série de Taylor, e o número de termos que a série terá, ou seja, a sua ordem, é dada em função da intensidade do coefiente $\lambda$ (Equações 21 e 22).

$$
\begin{array}{ll}
E=E_{0}+\lambda^{1} E_{1}+\lambda^{2} E_{2}+\ldots & \text { (Equação 21) } \\
\psi=\psi_{0}+\lambda^{1} \psi_{1}+\lambda^{2} \psi_{2}+\ldots & \text { (Equação 22) }
\end{array}
$$

Se $\lambda=0, E=E_{0}$, temos portanto a solução não perturbada do sistema.

A perturbação é uma correção para a correlação eletrônica [Møller, 1934], e a adição de mais termos melhora descrição do sistema. para $\lambda=1$, temos a solução idêntica à obtida por Hartree-Fock. Se $\lambda=2$ r a correção chama-se MP2. Por outro lado, espera-se que a adição de mais termos faça com que o valor da energia convirja para um resultado onde todas as correlações estejam incluídas, mas não é o que acontece, pois a convergência não é uniforme. $\mathrm{O}$ aditamento de outros termos gera resultados que oscilam em torno da solução exata do problema. Não explica-se este fato, e acredita-se que a variação que ocorre é devida ao tamanho da perturbação em relação ao hamiltoniano não perturbado, que seria grande demais. Existem também outras explicações que estão relacionadas com a estrutura molecular [Cremer, 1996] ou com as propriedades espectroscópicas do sistema [Christiansen, 1996], entretanto não há um consenso. Na prática, utilizam-se somente os métodos MP2 e MP4, que dão resultados mais coerentes, mas não o MP3.

\section{iv. Método do Conjunto Completo de Funções de Base}


O método do Conjunto Completo de Funções de Base [Nyden, 1981], ou CBS, pertence à classe dos métodos compostos. Este tipo de metodologia foi desenvolvida a partir de algumas observações: geometrias otimizadas com bases pequenas em níveis de teoria baixos são tão boas quanto aquelas otimizadas em métodos abrangentes e em bases mais extensas, com a diferença de que os primeiros são computacionalmente mais baratos, tanto no referente ao tempo de processamento como no tocante às quantidades de disco rígido e memória RAM necessários. Outra observação refere-se às correções para a energia total da molécula, cujas contribuições diminuem à medida que o nível de teoria e a extensão da base vão aumentando.

O truncamento das funções de base monoeletrônicas é a maior fonte de erro em cálculos de energia [Foresman, 1996]. Com base nesta pressuposto, foi desenvolvido o método de extrapolação dos resultados de cálculos de energia por teoria de perturbação para o limite de um conjunto completo de funções de base, que seria atingido pela convergência assintótica da série de pares de orbitais naturais. O método CBS otimiza a geometria molecular e calcula suas freqüências nưma base relativamente pequena num método Hartree-Fock ou de perturbação. Posteriormente são computados valores de energia por teoria de perturbação em bases maiores e feitas correções empíricas dos valores.

Existem algumas versões do método CBS. Há o CBS-4, o CBS-Q e o CBS-APNO, em ordem crescente de precisão. O método utilizado nesta dissertação foi o CBS-4, que era o único possível dado o tamanho das moléculas que foram estudadas neste trabalho. As etapas do método estão no Esquema 1.

\begin{tabular}{l|l}
\hline \multicolumn{1}{c|}{ Etapa } & \multicolumn{1}{c}{ Operação de cálculo } \\
\hline otimização de geometria & $\mathrm{HF} / 3-21 \mathrm{G}(\mathrm{d})$ \\
\hline freqüencias & $\mathrm{HF} / 3-21 \mathrm{G}(\mathrm{d})$ \\
\hline energia do SCF & $\mathrm{HF} / 6-311+\mathrm{G}(3 \mathrm{~d} 2 \mathrm{f}, 2 \mathrm{df}, \mathrm{p})$ \\
\hline correlação de segunda ordem & $\mathrm{MP} 2 / 6-31+\mathrm{G} \dagger$ \\
\hline configurações para extrapolação & $\geq 5$ \\
\hline correlações de ordem alta & $\mathrm{MP} 4(\mathrm{SDQ}) / 6-31 \mathrm{G}$ \\
\hline correções empíricas & para 1 e 2 elétrons e contaminação de spin \\
\hline
\end{tabular}

Esquema 1. Etapas de cálculo do método CBS-4.

\section{v. Teoria do Funcional de Densidade}


Para obter resultados de boa exatidão, recomendam-se os métodos de Interação de Configuração (CI), Møller-Plesset (MP), multi-configuracional(MCSCF) [Yamamoto, 1996] e coupled cluster(CC) [Pople, 1987]. Nestas metodologias são feitos cálculos considerando diferentes configurações eletrônicas além da fundamental. Contudo, seu alto custo computacional limita a sua aplicação a sistemas maiores.

Os métodos baseados na teoria do funcional de densidade (DFT) oferecem uma abordagem diferente para o problema da correlação eletrônica ingnorada por Hartree-Fock. Além disso, a adição de um potencial de intercâmbio de correlação corrige a interação do elétron consigo próprio.

Pela teoria do funcional de densidade o valor da energia é obtido diretamente da densidade eletrônica. Um funcional é uma função composta, e no caso da teoria do funcional de densidade ele é aplicado sobre a função densidade eletrônica do sistema para determinar a sua energia. Como a correlaçăo intereletrônica pode ser escrita em função da densidade eletrônica, pode-se encontrar um potencial de correlação a partir deste resultado. O primeiro potencial de correlação desenvolvido [Slater, 1963], foi chamado de potencial $X_{\alpha}$ onde $\alpha$ é um parâmetro de escala do potencial.

A energia calculada com o método DFT é calculada pela equação 23 [Hehre et al., 1998].

$$
E=E^{\text {nuclear }}+E^{\text {interna }}+E^{\text {coulombiana }}+E^{X^{X}}(P)+E^{C}(P)
$$

$\mathrm{Na}$ equação acima $\mathrm{E}^{\text {nuclear }}$ é a repulsão internuclear, $\mathrm{E}^{\text {interna }}$ é a energia cinética eletrônica e a atração coulombiana entre elétrons e núcleos e $\mathrm{E}^{\text {coulombiana }}$ é a repulsão intereletrônica. Estes três termos existem na energia calculada por Hartre-Fock. O termo de intercâmbio eletrônico de Hartree-Fock é substituído na Teoria do Funcional de Densidade por $\mathrm{E}^{\mathrm{X}}(\mathrm{P})$, e é adicionado o termo de correlação $\mathrm{E}^{\mathrm{C}}(\mathrm{P})$. Estes dois termos são função da densidade eletrônica $(P)$.

O modelo DFT mais simples é o da densidade local, onde a expressão dos funcionais de densidade de spin vem da solução exata de um gás de elétrons. Já os modelos de gradiente corrigido, que incluem o gradiente da densidade spin, são chamados de não locais. Além disso, procura-se um funcional de densidade ideal, cuja unicidade foi estabelecida pelo teorema de Hohenberg-Kohn [Hohenberg, 1964], mas cuja forma não foi encontrada até hoje.

Nesta dissertação foram usados dois métodos de funcional de densidade: o Becke-Perdew perturbativo, pBP [Becke, 1988 e Perdew, 1986] e o de Becke-Lee, Yang e Parr, B3LYP [Lee, 1988]. Ambos utilizam o funcional de Becke e diferem nas correções, dadas pelo gradiente de densidade de spin. Esta correções são necessárias pois o funcional de Becke considera modelo de densidade local. Se a correção é feita após a convergência do funcional, o que é computacionalmente mais vantajoso do que o cálculo a cada correção, temos um método perturbativo, como o pBP. O método pBP foi usado com uma base exclusiva do pacote Spartan 5.0, identificada com DN**. Este conjunto de base é semelhante ao 6-31G** [Hehre et al., 1998]. 


\section{vi. Métodos Semi-empíricos}

As ferramentas de cálculo semi-empíricas são computacionalmente mais baratas pois parâmetros experimentais ou resultados de cálculos $a b$ initio são introduzidos para substituir o cálculo de integrais, e certas integrais de dois centros e todas as de 3 e 4 centros são anuladas. Neste aspecto, os métodos atingem plenamente os seus objetivos, a ponto de permitir que sistemas extremamente grandes, como por exemplo moléculas de proteínas, sejam tratados. Pode-se considerar métodos DFT ou CBS como semi-empíricos, pois eles são desenvolvidos para que o melhor resultado seja encontrado, e não há uma preocupação formal como nos métodos ab initio.

A otimização de geometria com um método semi-empírico pode ser usada para diminuir o tempo de processamento da otimização de geometria num método mais rigoroso. Por outro lado, os métodos semi-empíricos têm graves limitaçōes. Se uma molécula contiver um átomo cujos parêmetros atômicos não estejam bem ajustados, todo o resultado estará comprometido. Além disso, certos sistemas são modelados erroneamente por estas técnicas, como por exemplo ligações de hidogênio, estados de transição, estados excitados, dentre outros.

Os métodos semi-empíricos estão baseados na Combinação Linear de Orbitais Atômicos, mas os elétrons internos não são incluídos na combinação. Dessa forma, a carga do núcleo fica diminuída pela inclusão da carga dos elétrons, e o potencial fica alterado. Este potencial é inserido numa hamiltoniana que inclui também o operador de energia cinética, e então a equação de Fock é resolvida, porém não da maneira dos métodos $a b$ initio, mas substituindo as integrais a serem calculadas a partir do potencial por parâmetros já existentes no programa.

O método semi-empírico usado nesta dissertação foi o PM3 [Stewart, 1994]. É um método de campo auto-consistente, onde consideram-se a repulsão eletrostática e a estabilização de intercâmbio. A função de base considera um orbital s e três orbitais p para todos os átomos. 


\section{vii. Modelos de solvatação}

Em cálculos $a b$ initio, que partem unicamente das posiçðes dos núcleos e da carga elétrica e spin totais, consideram-se moléculas isoladas numa fase gasosa. Para estudar moléculas sob influência do meio, existem modelos de solvatação que são usados em métodos que foram agrupados aqui em algumas categorias.

A primeira encerra métodos baseados na construção de funções que descrevem os potenciais de interação entre as partículas a partir da expansão virial da equação de estado [Barker, 1976]. Estes potenciais são bastante simplificados e não levam em consideração aspectos relevantes à química dos sistemas, $\mathrm{e}$ por isso são de limitada aplicação.

A segunda classificação é a baseada na simulação computacional de líqüidos [Allen, 1987], cujos representantes principais são o Método de Monte Carlo [Metropolis, 1957 e Coutinho, 1997] e a Dinâmica Molecular[Alder, 1957 e Kuschik, 1977]. Esta é uma abordagem parecida com a primeira , onde estabelecese um potencial e regras de evolução temporal do sistema, mas que modela melhor sistemas de interesse químico do que os métodos da primeira categoria.

A terceira abordagem, que é a utilizada neste trabalho, é a do dielétrico contínuo [Tomasi, $1994 \mathrm{e}$ Truong, 1998]. A solvatação é considerada um fenômeno onde cada molécula do soluto fica contida numa cavidade dentro de um meio isotrópico contínuo, cuja principal característica é a constante dielétrica. $\mathrm{O}$ primeiro desenvolvimento do assunto [Debye, 1929], foi baseado nas equações desenvolvidas por Born [Born, 1920]. O modelo da cavidade esférica [Onsanger, 1936] foi fundamental para o desenvolvimento das técnicas atuais. $O$ desenvolvimento de cavidades mais realístas como elipsóides [Rivail, 1982] e cavidades moleculares [Huron, 1974 e Tomasi, 1983] aumentou a exatidão e o alcance das técnicas. Neste trabalho foi usado o modelo de solvatação SM5.4 [Chambers, 1996] do AMSOL 6.6.

A quarta classe de abordagens é a supermolecular [Alagona, 1973 e Pullman, 1975], uma abordagem discreta criada para estudar detalhadamente o fenômeno da solvatação, onde as moléculas do solvente são consideradas da mesma forma que são consideradas as moléculas do soluto, ou seja, todos os cálculos são feitos para ambas as espécies presentes. Assim, este modelo permite estudar esferas e sítios moleculares de solvatação. Entretanto, em tal abordagem não considera-se efeito das moléculas do seio da solução na estrutura das esferas de solvatação. Além disso, o modelo é pontual, pois as interaçães ficam restritas aos sítios de solvatação específicos da molécula do soluto, não tratando uniformemente a espécie solvatada.

O quinto modelo é o da Ligação de Orbitais Naturais [Reed, 1988]. Este método é semelhante aos métodos supermoleculares, sendo que a diferença está na maneira com que a estrutura eletrônica é concebida. No caso da abordagem supermolecular clássica utilizam-se métodos da mecânica quântica, enquanto que no da Ligação de Orbitais Naturais consideram-se as interaçōes de pares eletrônicos de orbitais ligantes, que decairiam de maneira menos abrupta no espaço que os antiligantes. Estudam-se por este 
modelo principalmente as forças de van der Waals, que são usadas no tratamento de interações intermoleculares e conseqüentemente da solvatação.

A sexta maneira é a combinação do modelo do dielétrico contínuo com o supermolecular. Solvatam-se sítios do soluto com poucas moléculas de solvente e aplica-se a esta supermolécula o modelo do dielétrico contínuo. Esta abordagem discreto-contínua é usada para casos simples [Claverie, 1978].

A maneira com que os cálculos são feitos para o modelo do dielétrico contínuo é uma variação do método da perturbação utilizada em métodos ab initio. Introduz-se no operador de Fock uma função potencial de interação eletrostática para o espaço da cavidade. Esta função depende das coordenadas eletrônicas e nucleares e da constante dielétrica do meio. Normalmente, ainda é usada uma função de distribuição elétrica do soluto no lugar da função de onda. Daí em diante, não há mais diferenças em relação ao método utilizado no modelo do campo auto-consistente, pois todas as integrais e determinantes são comuns, a única diferença é o termo de interação eletrostática que simula a presença do solvente. 


\section{Resultados e discussão}

\section{i. Análise conformacional}

A diferença entre as duas séries de compostos é a existência de um grupo metileno adicional localizado no anel oposto às carbonilas (Figura 9).

Série I

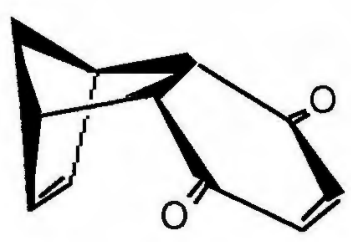

S11

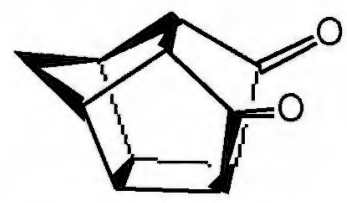

S12

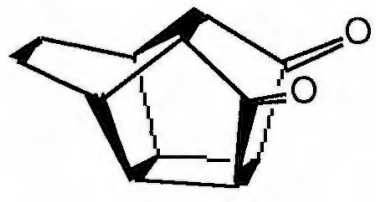

S22

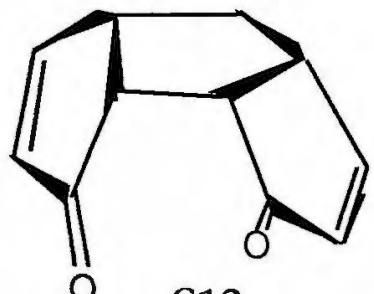

$\mathrm{S} 13$

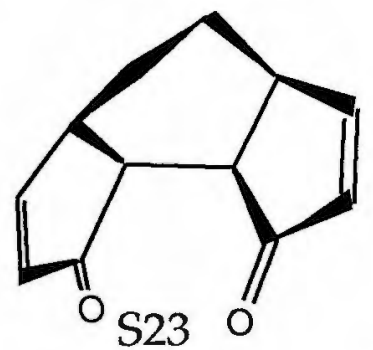

Figura 9. Estruturas das moléculas das séries I e II .

Foram estudadas as possibilidades conformacionais das moléculas, e encontraram-se três conformeros para S11 e S21 e dois para S23 (Figura 10). As geometrias foram otimizadas e caracterizadas como estados estacionários pelo cálculo de frequências vibracionais (Tabela 1).<smiles>O=C1C=CC(O)C2C3CC(C3)[C@H]12</smiles>

S11a

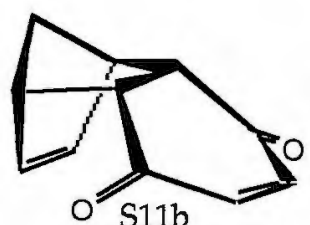

$\mathrm{O} \mathrm{S} 11 \mathrm{~b}$

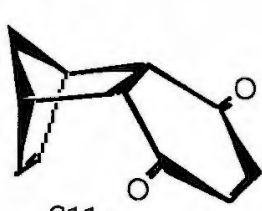

S11c
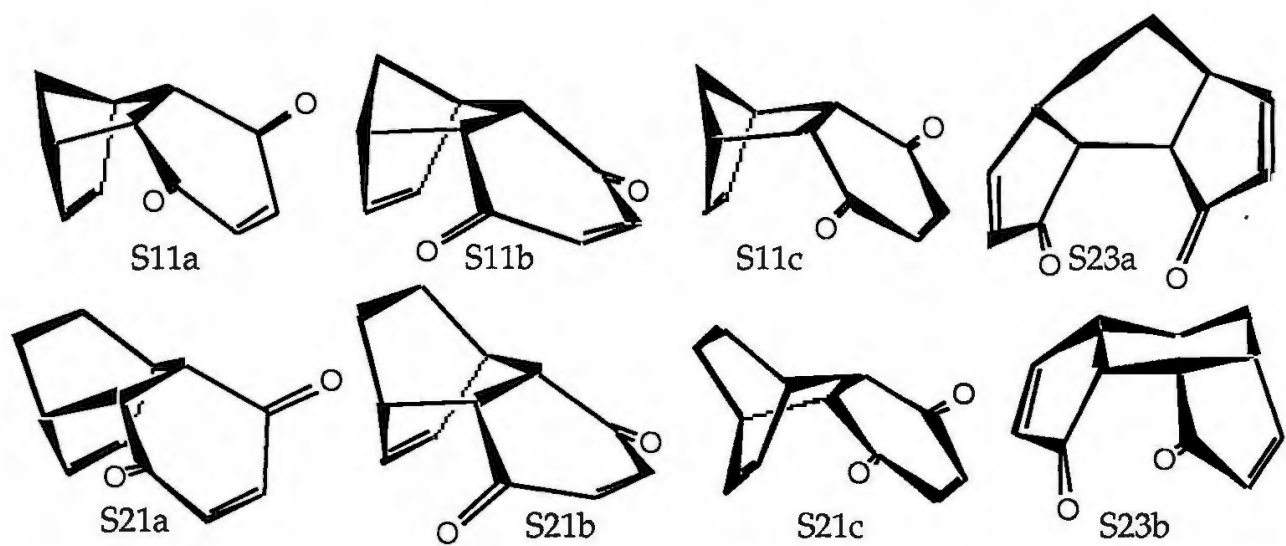

S21c

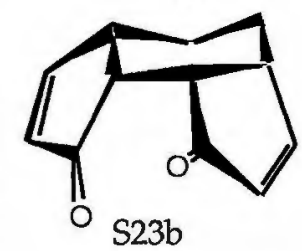

Figura 10. Conformações encontradas para as moléculas das séries I e II. 
Tabela 1. Energias eletrônicas somadas à energia da vibração a $0 \mathrm{~K}$ (Hartree). Geometrias otimizadas pelos métodos e bases $\mathrm{pBP} / \mathrm{DN}^{* *}, \mathrm{pBP} / \mathrm{DN}^{*}$, B3LYP/3-21G* e HF/3-21G*, para as duas séries de compostos.

\begin{tabular}{|c|c|c|c|c|}
\hline molécula & $\mathrm{pBP} / \mathrm{DN}^{* *}$ & $\mathrm{pBP} / \mathrm{DN}^{*}$ & $\mathrm{~B} 3 \mathrm{LYP} / 3-21 \mathrm{G}^{*}$ & $\mathrm{HF} / 3-21 \mathrm{G}^{*}$ \\
\hline S11a & -575.617314 & -575.594378 & não encontrado & não encontrado \\
\hline & -575.618301 & -575.595189 & -572.235947 & -568.662463 \\
\hline S17 & -575.616586 & -575.593688 & não encontrado & não encontrado \\
\hline 521 & -614.925529 & -614.925529 & não encontrado & não encontrado \\
\hline & -614.927930 & -614.927474 & -611.325179 & -607.482712 \\
\hline & -614.928726 & não encontrado & não encontrado & não encontrado \\
\hline & -575.627608 & -575.606142 & -572.267823 & -568.695962 \\
\hline & -614.925657 & -614.900699 & -611.339888 & -607.482712 \\
\hline & -575.632534 & -575.609389 & não encontrado & -568.680079 \\
\hline & -614.936382 & -614.909350 & não encontrado & -607.473986 \\
\hline & -614.930581 & -614.903263 & não encontrado & -607.464617 \\
\hline
\end{tabular}


As conformações encontradas para S11 e S21 correspondem às possibilidades do ângulo diédrico entre a ligação $\mathrm{C}=\mathrm{O}$ e a ligação $\mathrm{C}=\mathrm{C}$ do anel enediônico. A existência de dois carbonos saturados néste anel força os ângulos formados pelos carbonos carbonílicos com os cabonos saturados para valores entre $120^{\circ}$, que é o ângulo formado pelas ligações de um carbono $\mathrm{sp}^{2}, \mathrm{e} 109^{\circ} 30^{\prime}, \mathrm{o}$ ângulo entre as ligações de um carbono tetraédrico. A resultante destas forças leva à formação de ângulos diédricos entre a ligação $\mathrm{C}=\mathrm{O} \mathrm{e}$ as ligações $\mathrm{C}-\mathrm{C}$ e $\mathrm{C}=\mathrm{C}$ diferentes de $180^{\circ}$, onde haveria um anel planar. As possibilidades em que uma das carbonilas encontra-se coplanar com a ligação $\mathrm{C}=\mathrm{C}$ também não foram encontradas.

A 2-ciclohexeno-1-4-diona (Figura 11), modelo da porção enediônica das moléculas S11 e S21, também não apresenta a conformação planar. Esta conformação implica em hidrogênios eclipsados nos carbonos saturados. Nesta molécula, os planos das carbonilas encontram-se voltados para lados diferentes da molécula. Ou seja, a conformação é parecida com uma conformação cadeira de um ciclohexano. Esta conformação da 2-ciclohexeno-1-4-diona assemelha-se à conformação das S11c e S21c.

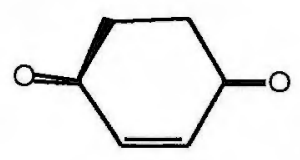

Figura 11. 2-ciclohexeno-1-4-diona.

Foram determinadas distâncias interatômicas e ângulos planos e diédricos formados pelas ligações das moléculas para caracterizar as estruturas das conformações encontradas (Tabela 2). 
Tabela 2. Ângulos diédricos (graus), distâncias interatômicas $(\AA)$ e diferenças de energia entre as conformações encontradas $\left(\mathrm{kcal}^{\left.-m_{0}{ }^{-1}\right)}\right.$ para as moléculas $\mathrm{S} 11\left(X=\mathrm{CH}_{2}\right)$ e S21 $\left(X=\mathrm{C}_{2} \mathrm{H}_{4}\right)$ e para a 2-ciclohexeno-1-4-diona obtidos pela otimização das geometrias por $\mathrm{pBP} / \mathrm{DN}^{* *}$.

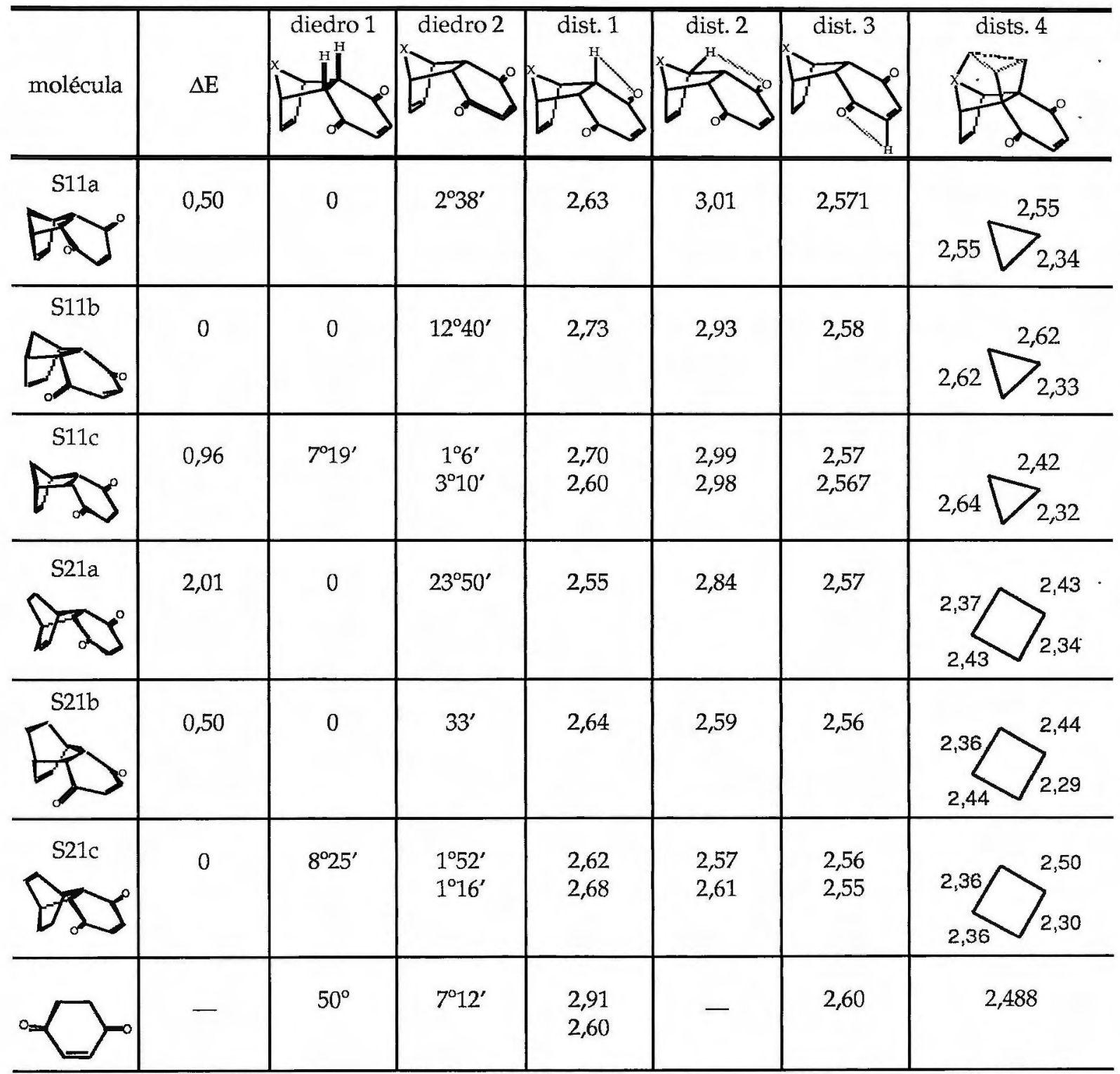

As diferenças de energia entre as conformações, calculadas com os valores de energia eletrônica e de energia do ponto zero, mostram que o confôrmero mais estável da molécula S11 é o S11b, que apresenta as carbonilas voltadas para "baixo".

Observa-se que o diedro 1 de S11c $\left(7^{\circ} 19^{\prime}\right)$ é o único em que os hidrogênios não estão eclipsados. Isso deve baixar a energia em relação às demais espécies, pois no composto modelo o diedro é de $50^{\circ}$. Por outro lado, os números da coluna dists. 4 mostram que este diedro não significou aumento de distância entre os hidrogênios, que é muito parecida em todos os compostos, o que significa que o diedro formado 
não foi suficiente para afastar os hidrogênios e diminuir apreciavelmente a repulsão eletrostática. Nesta mesma coluna da tabela é visto que a distância entre os hidrogênios considerados têm os maiores valores em S11b e em S11c há a menor distância entre estes hidrogênios, o que causa uma instabilização pelo aumento da repulsão. Este é provavelmente o fator determinante da ordem de estabilidade dos confôrmeros. A conjugação dos orbitais $\mathrm{p}$ em $\mathrm{S} 11 \mathrm{~b}$ deve ter sido pouco prejudicada pela diferença de $12^{\circ} 40^{\prime}$ em relação ao ângulo raso. As distâncias 1, 2 e 3, que são do oxigênio carbonílico até os hidrogênios mais próximos mostram que em $\mathrm{S} 11 \mathrm{~b}$ as distâncias são as maiores observadas, o que caracteriza baixa repulsão eletrônica e confirma a maior estabilidade de S11b.

Para os confôrmeros de S21 o perfil energético é diferente, com a S21c como molécula mais estável. S21a é a mais instável provavelmente devido ao alto desvio do plano das carbonilas em relação ao plano da ligação $C=C$, o que deve ter causado uma queda da conjugação suficiente para torná-la a molécula menos estável da série. Este deve ser o fator predominante na instabilização desta molécula, pois os demais resultados são comparativamente satistatorios. Para explicar a maior estabilidade de S11c em relação a S11b, observa-se que as distâncias 1, 2 e 3 são parecidas, e que provavelmente o balanço destas pequenas diferenças foi mais favorável a S11c que a S11b. O fenômeno da aproximação dos hidrogênios observado em S11c é menos intenso em S21c, pois no caso da primeira a diferença em relação à espécie mais estável é de $0,2 \AA$, enquanto que no caso da segunda a diferença é de $0,08 \AA$. Além disso, a distância em que foi observado um afastamento entre os hidrogênios também tem uma diferença maior entre S21c e S21b do que entre S11c e S11b, sendo o aumento 0,06 $\AA$ na segunda série e 0,02 $\AA$ na primeira. Ou seja,o afastamento foi maior e a aproximação menor, o que favoreceu S21c na segunda série, diferente do observado na primeira.

Para as moléculas S12 e S22, as cetonas-gaiola, foi encontrada uma única conformação para cada molécula. Foram encontrados dois confôrmeros para S23, mas não para S13. Para ambas há a possibilidade de uma conformação simétrica (Figura 12), mas esta possibilidade não foi encontrada.

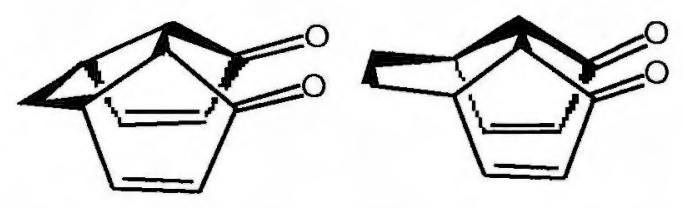

Figura 12. Conformações de S13 e S23 simétricas em relação ao plano de simetria. Não encontradas.

A S13 possui um anel saturado de cinco membros análogo ao ciclopentano, que possui uma única conformação. Este fato também foi observado em S13; daí a existência de uma única conformação. A S23 tem um anel análogo ao ciclohexano, que possui duas conformaçóes possíveis: a conformação cadeira (mais estável) e o barco "twist" ou torcido. Estas duas possibilidades foram encontradas na molécula S23, e os seus parâmertros estruturais foram estudados como no caso das substâncias S11 e S21 (Tabela 3). 
Tabela 3. Ângulos planos e diédricos (graus), distâncias interatônicas $(\AA)$ e diferenças de energia $\left(\mathrm{kcal}^{\prime} \mathrm{mol}^{-1}\right)$ para os confôrmeros das moléculas S23 e S23b.

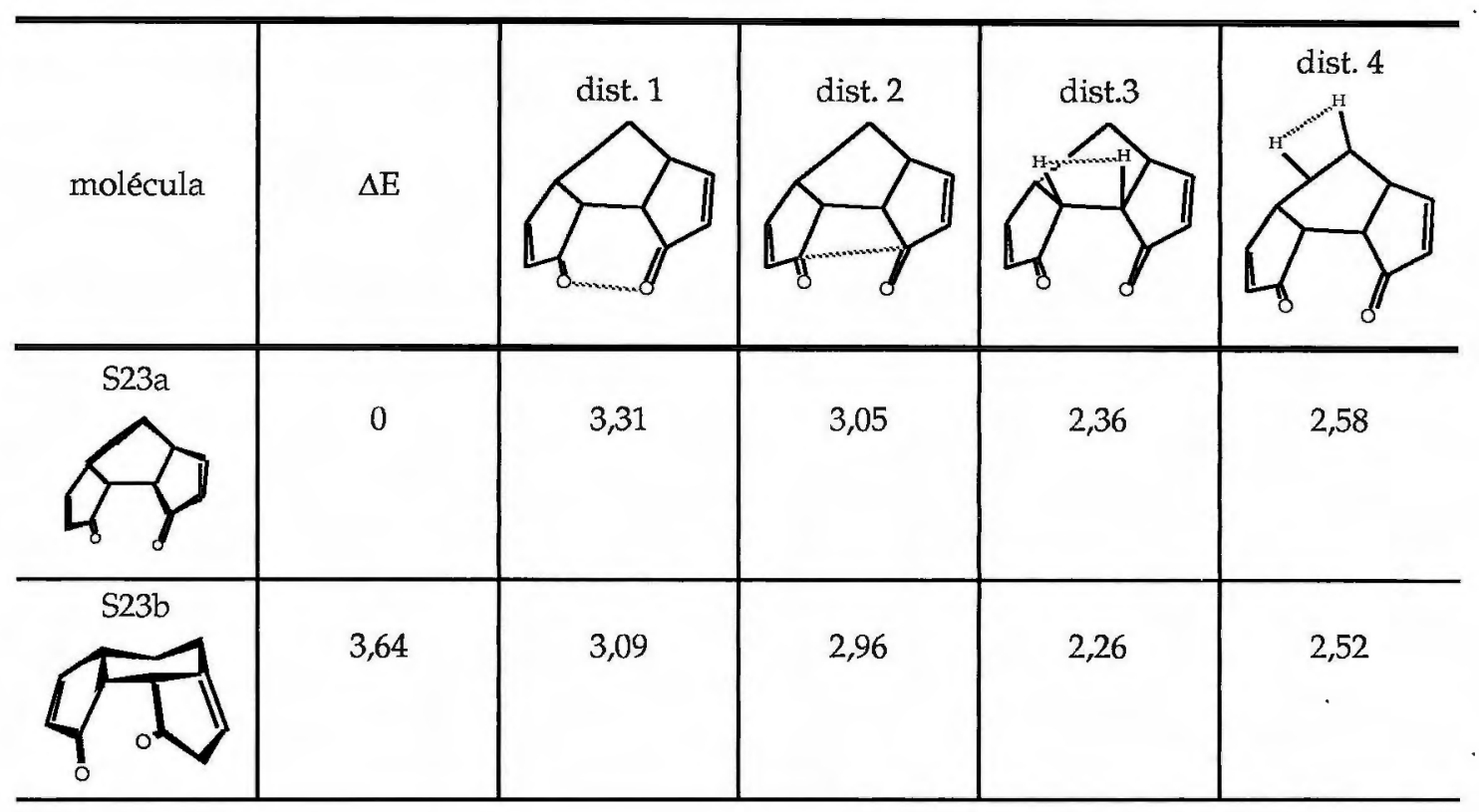

A conformação S23b, na qual o ciclohexano aparece na coformação cadeira, que deveria ser mais estável de acordo com a análise conformacional do ciclohexano [Carrol, 1998], é menos estável. Este resultado é explicado pelas menores distâncias interatômicas em todos os casos observados, que são os mais importantes pois envolvem átomos pesados e hidrogênios próximos. 


\section{ii. Calores de isomerização}

O estudo computacional mais natural das cetonas de Cookson é o das entalpias de isomerização, devido aos resultados experimentais existentes e devido também ao fato das moléculas serem isômeros de estrutura parecida, o que torna a comparação de resultados computacionais com experimentais confiável. Foram calculadas as energias de isomerização por vários métodos (Tabela 4).

Tabela 4. Energias de isomerização calculadas e determinadas [Cookson, 1964] $/ \mathrm{kcal} \mathrm{mol}^{-1}$

\begin{tabular}{l|l|l}
\hline & método & \\
\hline $\mathrm{CBS}-4 / / \mathrm{HF} / 3-21 \mathrm{G}^{*}$ & $-42,58$ & $-49,59$ \\
\hline $\mathrm{pBP} / \mathrm{DN}^{* *} / / \mathrm{pBP} / \mathrm{DN}^{* *}$ & $-5,84$ & 1,43 \\
\hline $\mathrm{pBP} / \mathrm{DN}^{*} / / \mathrm{pBP} / \mathrm{DN}^{*}$ & $-6,87$ & 2,65 \\
\hline $\mathrm{MP} 4 \mathrm{SDQ} / 6-31 \mathrm{G} / /$ & 0,95 & 7,86 \\
$\mathrm{pBP} / \mathrm{DN}^{* *}$ & $-5,97$ & $-0,14$ \\
\hline $\mathrm{HF} / 6-31+\mathrm{G}^{* *} / / \mathrm{pBP} / \mathrm{DN}^{* *}$ & $-7,77$ & $-0,63$ \\
\hline $\mathrm{HF} / 6-31 \mathrm{G}^{* *} / / \mathrm{pBP} / \mathrm{DN}^{* *}$ & $-8,28$ & $-11,93$ \\
\hline $\mathrm{HF} / 6-31 \mathrm{G}^{*} / / \mathrm{pBP} / \mathrm{DN}^{* *}$ & $-23,13$ & $-9,22$ \\
\hline $\mathrm{HF} / 3-21 \mathrm{G}^{*} / / \mathrm{pBP} / \mathrm{DN}^{* *}$ & $-20,00$ & 3,47 \\
\hline $\mathrm{B} 3 \mathrm{LYP} / 3-21 \mathrm{G}^{*} / /$ & 7,07 & $-9,83$ \\
\hline $\mathrm{B3LYP} / 3-21 \mathrm{G}^{*}$ & $-20,96$ & $-4,23$ \\
\hline $\mathrm{pBP} / \mathrm{DN} / / \mathrm{pBP} / \mathrm{DN}$ & $-11,32$ & \\
\hline $\mathrm{HF} / 3-21 \mathrm{G}^{*} / / \mathrm{HF} / 3-21 G^{*}$ & & \\
\hline experimental & & \\
\hline
\end{tabular}

$\mathrm{Na}$ tabela acima são mostradas equações químicas de ciclizações [2+2] induzidas pela luz. As reaçōes estão num único sentido, sem a via térmica de abertura do anel, pois a intenção é somente mostrar o reagente e o produto considerados para fazer as contas.

A razão para que tantos cálculos fossem feitos é devida à tentativa de explicação da concordância dos resultados com os valores experimentais. Como os métodos possuem diferenças na maneira de considerar as estruturas, as concordâncias serão diferentes entre si, e por isto são necessários muitos estudos para tentar identificar a causa da não concordância. Ao comparar os resultados obtidos por CBS-4 e HF/3$21 G^{*}$, que é o método de otimização de geometrias usado no CBS-4, nota-se que os resultados para HF/3- 
21G* estão mais próximos dos valores experimentais que o CBS-4, ou seja, as correções que deveriam aproximar os resutados calculados dos experimentais, aparentemente os afastaram.

A otimização de geometria com o método $\mathrm{pBP}$ nas bases $\mathrm{DN}^{*} \mathrm{e} \mathrm{DN}^{* *}$ mostrou resultados muito mais satisfatórios para os valores de energia de isomerização. O resulado com a base DN não obteve tal sucesso, o que indica a importância de utilizar funções de polarização para estudar sistemas cíclicos. Pela sua boa concordância, foi escolhida a geometria otimizada com o método $\mathrm{pBP} / \mathrm{DN}^{* *}$ para estudar o efeito da base no valor da energia. Os resultados mostram que a utilização desta geometria em cálculos de energia com o método HF em diferentes bases causa uma melhora na concordância dos resultados calculados com os experimentais, o que é naturalmente esperado.

Pode ainda ser observado que os resultados estão divididos em dois grupos. Num grupo estão métodos cujos resultados de calor de isomerização são mais negativos que os valores experimentais (CBS4, HF/3-21G*//pBP/DN**, B3LYP/3-21G*//B3LYP/3-21G* e HF/3-21G*//HF/3-21G*). No outro grupo estão os demais métodos, cujos resultados são mais positivos que os valores experimentais.

Observa-se que no primeiro grupo as moléculas tiveram suas geometrias otimizadas ou suas energias calculadas na base $3-21 G^{*}$, que é pequena. No outro grupo as geometrias estão otimizadas em bases melhores e cujas energias também são calculadas em bases melhores.

Estes resultados permitem levantar a hipótese de que os resultados para as moléculas-gaiola podem ser sistematicamente diferentes dos obtidos para as moléculas abertas. No caso dos calores de reação mais positivos, se pode supor que as moléculas-gaiola sejam avaliadas como mais instáveis, ou as moléculas abertas como mais estáveis, do que elas realmente são. O oposto se espera para o grupo dos calores de reação mais negativos. Apresar de ser possível concluir que haja uma diferença no tratamento das moléculas, os resultados não permitem decidir qual é a espécie melhor calculada em cada caso.

Esta hipótese da diferença no cálculo dos calores de isomerização pode ser levantada também para o caso da segunda isomerização das moléculas-gaiola (Tabela 5)

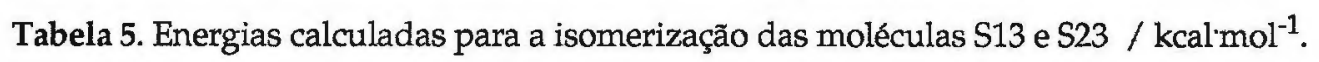

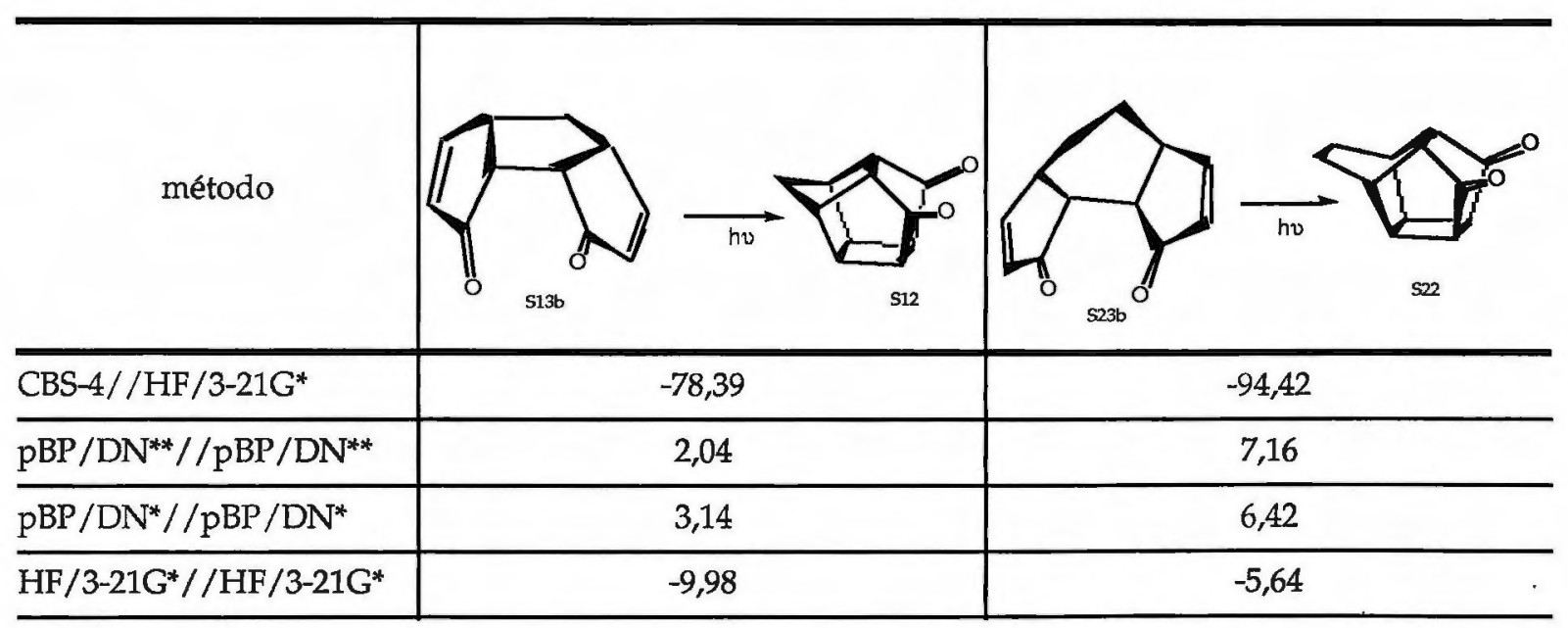


Apesar de não haver resultados experimentais para comparar, observa-se que as diferenças energéticas calculadas por CBS-4 são muito altas, e não há nenhuma razão para esperar que os valores experimentais sejam assim. Os resultados calculados com os métodos DFT são significativamente mais positivos, o que agrupa os resultados de maneira idêntica à observada na primeira isomerização. Como a reação destas moléculas foi proposta para acumular energia, espera-se que a isomerização via luz seja um processo endotérmico, como prevêem os resultados por DFT. Como CBS-4 e HF/3-21G* indicam o oposto, a hipótese de que as suas energias são calculadas de maneira diversa fica evidencidada.

Além da hipótese considerada, falhas no cálculo de calores de formação de diferentes tipos de moléculas com métodos de conjunto completo de funções de base já foram observados anteriormente [Curtiss, 1998]. Para o naftaleno, a maior molécula então estudada, os métodos CBS não produziram resultados concordantes para a entalpia de formação. No caso do CBS-4, a diferença em relação ao experi-

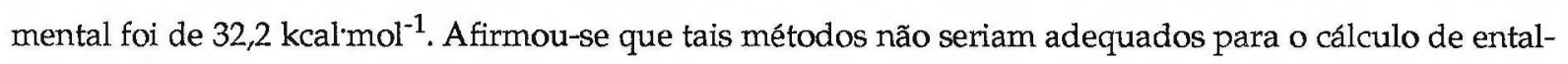
pias de formação de moléculas grandes, principalmente de hidrocarbonetos. Os autores do método responderam que na versão Gaussian 98 havia correções no truncamento do conjunto de funções de base, que geravam autovalores incorretos e diminuiam a precisão do método CBS-4 do Gaussian 94 [Montogomery Jr., 1998]. Entretanto, estas correções não foram suficientes para eliminar os problemas observados no método CBS-4, pois a diferença em relação ao experimental permaneceu alta: $18,3 \mathrm{kcalmol}^{-1}$.

Entretanto, para decidir se o método CBS-4 realmente não é adequado para calcular moléculas grandes, ou se a hipótese da diferença no tratamento inerente a todos os métodos é a verdadeira, são necessários outros resultados, preferencialmente se for possível comparar com resultados experimentais. É o que foi feito para os calores de combustão destas moléculas, apresentados na seção seguinte.

\section{iii. Calores de combustão}

Antes de iniciar a discussão sobre os resultados obtidos, cabe aqui um comentário sobre os resultados experimentais a partir dos quais as comparações serão efetuadas. O método experimental para a determinação da entalpia de combustão consiste na queima de uma amostra sólida num calorímetro, incluindo portanto a entalpia de sublimação dos compostos, que para o caso de 512 é de $22,1 \mathrm{kcal} / \mathrm{mol}$ [Jimenez, 1999]. O calor de combustão para S12 apresentado na Tabela 7 [Cookson, 1964] foi medido também por Jimenez e colaboradores [Jimenez, 1999] com boa concordância entre as medidas. Como o cálculo efetuado neste trabalho refere-se à combustão a partir da fase gasosa, as comparações foram efetuadas supondo que as diferenças de entalpia de sublimação são pequenas. Este valor representa $c a$. de 1,5\% do valor experimental ( $c a$. de $20 \mathrm{kcal}$ ). Apesar de significativo, este valor não altera o comportamento dos desvios entre os valores calculados e experimentais, pois o acréscimo seria muito parecido em todos os méto- 
dos. A suposição de que todos os calores de sublimação são muito próximos não é absurda, pois o calor de sublimação da benzoquinona é ca. $15 \mathrm{kcal} / \mathrm{mol}$ [Coolidge, 1927]. A adição de um outro anel de cinco membros deve elevar este valor para próximo de $20 \mathrm{kcal} / \mathrm{mol}$.

Foram calculados os calores de combustão das moléculas S11b e S12 da série I e das moléculas S21b e S22 da série II (Tabela 6), segundo as reaçōes:

$$
\begin{array}{llll}
\mathrm{C}_{11} \mathrm{H}_{10} \mathrm{O}_{2}+12,5 \mathrm{O}_{2} & \rightarrow 11 \mathrm{CO}_{2}+5 \mathrm{H}_{2} \mathrm{O} & \text { (Equação 31) } \\
\mathrm{C}_{12} \mathrm{H}_{12} \mathrm{O}_{2}+14 \mathrm{O}_{2} & \rightarrow 12 \mathrm{CO}_{2}+6 \mathrm{H}_{2} \mathrm{O} & \text { (Equação 32) }
\end{array}
$$

Tabela 6. Calores de combustão calculados e experimentais [Cookson, 1964] para as moléculas da série.I

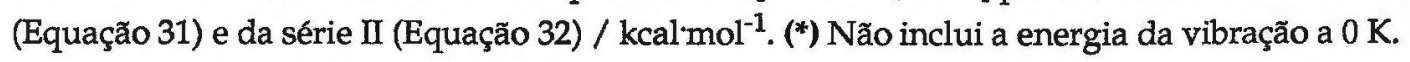

\begin{tabular}{l|l|l|l|l}
\hline & & & \\
\end{tabular}


Os resultados foram obtidos pela diferença das energias calculadas para as estruturas otimizadas de reagentes e produtos, somados à diferença das energias de vibração a zero kelvin obtidas do cálculo de freqüências vibracionais. Não foi feita a correção dos valores de energia do ponto zero por fator algum. Esta correção, baseada numa média de correções para moléculas cujas freqüências foram calculadas e comparadas com valores experimentais, pode não ser adequada para os compostos estudados. Para encontrar tal valor seria necessário um estudo das freqüências vibracionais das moléculas em cada um dos métodos e como foram feitos cálculos em muitos métodos, seria necessário um número alto de fatores. Isto causaria uma complicação no tratamento dos dados cujo efeito seria ca. de $5 \%$ na energia do ponto zero, cujo valor médio para as moléculas estudadas é $c a$. de $120 \mathrm{kcal} / \mathrm{mol}$. Isso significa que o ganho não melhoraria a concordância com os resultados experimentais. Por estas razões não foram usados tais fatores de correção.

De um modo geral os resultados apresentados na Tabela 6 mostram que melhorias no método e na base melhoram a concordância dos valores calculados com os experimentais, ou seja, os valores calculados tornam-se mais negativos.

É interessante notar que o método CBS-4 é o que apresenta os valores mais próximos do experimental para as moléculas abertas (S11 e S21), e o método pBP/DN**é o que mais se aproxima dos valores

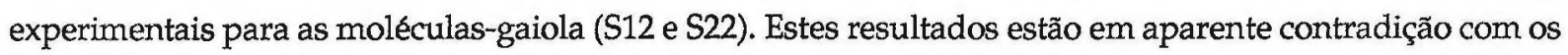
resultados obtidos para o calor de isomerização, em que os resultados mostram que o método CBS-4 dá um resultado muito afastado do valor experimental. Para avaliar a eficácia dos métodos em calcular os calores de combustão, foram calculados os erros absoluto e percentual dos valores da Tabela 6 em relação aos valores experimentais (Tabela 7) 
Tabela 7. Diferença absoluta (acima) e percentual (abaixo à direita) entre os resultados experimentais e os calculados de calores de combustão/ $\mathrm{kcal} \mathrm{mol}^{-1}$.

\begin{tabular}{|c|c|c|c|c|}
\hline método & $0^{2}$ & S12 & S21c & S22 \\
\hline $\begin{array}{l}\mathrm{CBS}-4 / / \\
\mathrm{HF} / 3-21 \mathrm{G}^{*}\end{array}$ & 78.91 & 109.49 & 90.71 & 136.30 \\
\hline $\begin{array}{l}\mathrm{pBP} / \mathrm{DN}^{* *} / / \\
\mathrm{pBP} / \mathrm{DN}^{* *}\end{array}$ & $\begin{array}{l}101.14 \\
\end{array}$ & 94.98 & 117.51 & 110.62 \\
\hline $\begin{array}{l}\mathrm{pBP} / \mathrm{DN}^{*} / / \\
\mathrm{pBP}^{\prime} / \mathrm{DN}^{*}\end{array}$ & 124,29 & 119,16 & 146,34 & 139,69 \\
\hline $\begin{array}{l}\text { MP4SDQ/6- } \\
31 \mathrm{G} / / \mathrm{pBP} / \mathrm{DN}^{* *}\end{array}$ & $\begin{array}{ll}164,51 & \\
& 12,3\end{array}$ & $\begin{array}{ll}153,46 & \\
& 11,6\end{array}$ & $\begin{array}{ll}189,64 & \\
& 12,8\end{array}$ & $\begin{array}{ll}177,77 & \\
& 12,0\end{array}$ \\
\hline $\begin{array}{l}\mathrm{HF} / 6-31+\mathrm{G}^{* *} / / \\
\mathrm{pBP} / \mathrm{DN}^{* *}\end{array}$ & $\begin{array}{l}191,67 \\
14,3\end{array}$ & $\begin{array}{ll}185,64 & \\
& 14,0\end{array}$ & $\begin{array}{ll}218,43 & \\
& 14,7\end{array}$ & $\begin{array}{ll}212,85 & \\
& 14,4\end{array}$ \\
\hline $\begin{array}{l}\mathrm{HF} / 6-31 \mathrm{G}^{* *} / / \\
\mathrm{pBP} / \mathrm{DN}^{* *}\end{array}$ & $\begin{array}{ll}205,66 & \\
& 15,3\end{array}$ & $\begin{array}{ll}201,44 & \\
& 15,2\end{array}$ & $\begin{array}{ll}236,22 & \\
& 15,9\end{array}$ & $\begin{array}{ll}232,36 & \\
& 15,7\end{array}$ \\
\hline $\begin{array}{l}\mathrm{HF} / 6-31 \mathrm{G}^{*} / / \\
\mathrm{pBP} / \mathrm{DN}^{* *}\end{array}$ & $\begin{array}{l}234,56 \\
\\
\end{array}$ & $\begin{array}{ll}230,84 & \\
& 17,4\end{array}$ & $\begin{array}{ll}271,17 & \\
& 18,3\end{array}$ & $\begin{array}{ll}267,79 & \\
& 18,1\end{array}$ \\
\hline $\begin{array}{l}\mathrm{HF} / 3-21 \mathrm{G}^{*} / / \\
\mathrm{pBP} / \mathrm{DN}^{* *}\end{array}$ & $\begin{array}{ll}278,90 & \\
& 20,7\end{array}$ & $\begin{array}{ll}290,03 & \\
& 21,8\end{array}$ & $\begin{array}{ll}318,58 & \\
& 21,5\end{array}$ & $\begin{array}{l}326,51,0 \\
\end{array}$ \\
\hline $\begin{array}{l}\text { B3LYP /3-21G*// } \\
\text { B3LYP/3-21G* }\end{array}$ & $\begin{array}{ll}279,86 & \\
& 20,9\end{array}$ & $\begin{array}{ll}287,87 & \\
& 21,7\end{array}$ & $\begin{array}{ll}324,81 & \\
& 21,9\end{array}$ & $\begin{array}{r}330,03 \\
\\
\end{array}$ \\
\hline $\begin{array}{l}\mathrm{pBP} / \mathrm{DN} / / \\
\mathrm{pBP} / \mathrm{DN}\end{array}$ & $\begin{array}{ll}303,93 & \\
& 22,7\end{array}$ & $\begin{array}{ll}299,70 & \\
& 22,6\end{array}$ & $\begin{array}{ll}342,69 & \\
& 23,1\end{array}$ & $\begin{array}{ll}335,21 & \\
& 22,6\end{array}$ \\
\hline $\begin{array}{l}\mathrm{HF} / 3-21 \mathrm{G}^{*} / / \\
\mathrm{HF} / 3-21 \mathrm{G}^{*}\end{array}$ & $\begin{array}{ll}304,20 & \\
& 22,7\end{array}$ & $\begin{array}{ll}313,15 & \\
& 23,6\end{array}$ & $\begin{array}{ll}347,27 & \\
& 23,4\end{array}$ & $\begin{array}{ll}353,10 & \\
& 23,8\end{array}$ \\
\hline
\end{tabular}

Como no caso dos calores de isomerização, pode ser observada a separação dos resultados em dois grupos. Num grupo estão métodos erros percentuais em relação ao experimental são menores para as moléculas abertas (CBS-4, HF/3-21G*//pBP/DN**, B3LYP/3-21G*//B3LYP/3-21G* e HF/3-21G*//HF/ $\left.3-21 G^{*}\right)$. No outro grupo estão os demais métodos, cujos erros percentuais em relação ao experimental são menores para as moléculas-gaiola. Este resultado comprova a hipótese formulada a partir dos resultados de calores de isomerização que os métodos com bases a partir do tamanho de 6-31G* calculam melhor as moléculas-gaiola. A observação dos erros percentuais também explica por que os resultados de calor de 
isomerização calculados por CBS-4 estão tão afastados dos valores experimentais. A diferença em relação ao experimental é muito diferente para cada uma das moléculas, o que causa a distorção observada. Este resultado mostra ainda que o calor de isomerização não é uma metodologia adequada para avaliar a eficácia dos métodos em modelar um sistema molecular. Apesar dos resultados absolutos para o calor de combustão serem muito grandes, eles mostram que o seu comportamento em relação ao experimental é coerente. Ou seja, não se pode usar os métodos de cálculo para prever calores de combustão, mas o comportamento dos seus erros relativos pode ser utilizado para compreender a concordância dos calores de isomerização.

A não concordância dos calores de combustão calculados com os experimentais é úm resultado esperado, pois numa reação de combustão os membros da equação química são muito diferentes, e por esta razão as diferenças absolutas para as cetonas de Cookson alcançaram valores de até $350 \mathrm{kcal} / \mathrm{mol}$. Como o estudo dos valores de calores de combustão foi feito com o objetivo de analisar o comportamento dos erros relativos, e não de encontrar um meio de prever entalpias de combustão, o cálculo é justificado.

Com base nos resultados apresentados, pode-se ainda extrapolar a diferença observada na concordância para calores de isomerização e combustão para o método de cálculo de entalpias de formação a partir de entalpias de reações isodésmicas. Os cálculos apresentados nesta dissertação mostram que a probabilidade do método de cálculo de entalpias de formação por reações isodésmicas falhar não é desprezível. $O$ cálculo de calores combustão por computação pode conter erros sistemáticos, que seriam eliminados caso a reação fosse isodésmica. Ou seja, como o número de ligações do mesmo tipo de ambos os lados da equação de combustão não é o mesmo, podem aparecer erros sistemáticos no cálculo das energias de ligação que cancelar-se-iam numa reação isodésmica. Como não existe uma maneira ab initio de calcular o calor de formação de uma substância, calcula-se a entalpia de uma reação isodésmica qualquer que envolva o composto de interesse e cuja entalpia de formação será obtida com valores experimentais de entalpias de formação das demais substâncias do processo. Já se sabe que o uso de reações isodésmicas pode causar erros, pois ele depende da reação escolhida para fazer os cálculos, e que muitas vezes são necessárias correç̃̃es [Petersson et al., 1998]. Mesmo assim, os resultados aqui apresentados mostram que além da subjetividade, o método de reaçõe isodésmocas pode falhar por não considerar o efeito das diferenças estruturais entre os dois membros da equação. Isto é, no caso do método de cálculo não considerar de maneira idêntica os reagentes e os produtos, como no caso das isomerizações calculadas, a entalpia de formação encontrada será totalmente incorreta, mesmo embora as moléculas estejam bem modeladas individualmente. Por não considerar a possibilidade de diferenças de cálculo causadas por diferenças estruturais, o cálculo de entalpias de formação de moléculas grandes por meio de reações isodésmicas está sujeito a erro.

Além disso, o método usado neste trabalho se mostra eficiente para a avaliação da exatidão dos métodos na descrição de moléculas grandes. $\mathrm{O}$ cálculo do calor de combustão de substâncias isômeras é razoável pois é subtraído um valor constante do resultado de cálculo, e o resultado pode ser comparado 
com medidas de calorimetria ou calculados com entalpias de formação. Caso as moléculas não sejam interconversíveis como no caso aqui estudado, a diferença entre os calores calculados e experimentais pode ser calculada, e assim pode-se ter um novo parâmetro de avaliação da aplicabilidade de métodos de cálculo a moléculas específicas.

Este procedimento não possibilita determinar qual a causa no método da não concordância com os valores experimentais. No caso das moléculas estudadas, os dados disponíveis não permitem decidir qual foi o defeito do CBS-4, mas permitem identificar duas possíveis fontes de erro, uma geometria otimizada numa base pouco acurada e correções que talvez falhem na avaliação de interações não-ligantes.

Assim, apesar da reação de combustão não ser isodésmica, para a qual o número de ligações de mesma ordem entre átomos iguais nos dois membros das equações devem ser os mesmos, pode-se utilizar os resultados da Tabela 7 para para avaliar o efeito da estrutura no resultado. Desta forma, espera-se inferir a infuência da aglomeração ou compactação de átomos e ligaçð̃es nos resultados obtidos por cálculo.

Feitas estas críticas aos meios de se calcular entalpias por computação, a discussão dos resultados pode ser retomada. Os resultados obtidos por Hartree-Fock em diferentes bases calculados sobre a geometria otimizada por $\mathrm{pBP} / \mathrm{DN}^{* *}$ mostram que o incremento da base melhora a concordância com os resultados experimentais. Este comportamento é esperado, pois o aumento do número de funções na base significa uma melhor descrição dos orbitais atômicos, e esta melhoria se reflete em orbitais moleculares mais realísticos. Nos cálculos de energia com a base $3-21 G^{*}$, os resultados com menor desvio em relaçăo ao experimental são as moléculas abertas, e nos resultados com bases de tamanho a partir do 6-31G, que é idêntica ao conjunto DN dos métodos pBP [Hehre, 1997], observam-se os menores desvios do calor de combustão nas moléculas-gaiola.

Este resultado pode causar a impressão de que as moléculas-gaiola são melhor calculadas que a moléculas abertas a partir de um certo nível de teoria, e que por esta razão o modelo de cálculo contém alguma falha na modelagem destas espécies. Esta hipótese não se confirma pois o resultado pode ser explicado pelas proprias características estruturais das moléculas.

Nas moléculas-gaiola os átomos encontram-se mais proximos, pois elas contém um anel de quatro membros e também possuem carbonilas mais próximas e numa posição favorárel à interação dos seus orbitais. Nas moléculas abertas as distâncias entre certos átomos não-ligados são mais longas, além da conjugação dos elétrons das duplas ligações, um tipo de interação de longa distância inexistente nas moleculas-gaiola. Estas diferenças são relevantes para avaliar os resultados, pois a melhoria do conjunto de funções de base, além de descrever melhor os orbitais, considera a probabilidade dos elétrons ocuparem regiões mais afastadas dos núcleos. As moléculas-gaiola formam estruturas mais compactas que as abertas, com átomos mais próximos, e os resultados indicam que conjuntos de base a partir de 6-31G, que é idêntico ao conjunto DN, são suficientes para diferenciar os resultados, pois a participação das interações não-ligantes deve estar melhor avaliada. 
Naturalmente, o aumento da base melhora também o resultado para as moléculas abertas, mas nestas espécies seria necessário um conjunto de funções de base maior para considerar interações nãoligantes dos seus átomos. Num conjunto completo de funções de base esperaria-se que os erros fossem os mesmos ou que as diferenças observadas fossem devidas a diferenças dos próprios modelos.

Entretanto, os resultados do calor de combustão para o conjunto completo de funções de base mostram uma melhor concordância para as moléculas abertas numa intensidade significativa. Para explicar este resultado, deve ser levado em conta que a otimização utilizada no método CBS-4 é HF/3-21G*. Esta otimização é provavelmente pior para as moléculas gaiolas, que são mais compactas, do que para as enedionas, que são abertas. Como a otimização satisfatória das moléculas-gaiola exigiria a utilização de uma base melhor, os resultados de energia provavelmente refletem este problema.

Trabalhos anteriores em sistemas com interações semelhantes mostram a relevância das interações não-ligantes [Hoffmann, 1971] para moléculas como as estudadas [Balaji, 1985 e Chow, 1989]. Nestes estudos são usadas técnicas de espectroscopia fotoeletrônica, de transmissão eletrônica, RMN e cálculos ab initio, e sugere-se que a interação entre os orbitais considerados é relevante para a avaliação do comportamento químico das espécies

Deste modo pode-se propor a hipotese de que os cálculos em compostos tipo gaiola são mais sensíveis à base, por levar em conta interações entre átomos não-ligados, e que os abertos são aparentemente mais sensíveis a uso da correlação eletrônica no método. Com o intuito de testar esta hipótese, foram feitos cálculos de deslocamento químico ( $\partial$ ) de ressonância magnética nuclear $(\mathrm{rmn})$ nestes compostos.

\section{iv. Cálculos de deslocamentos químicos de RMN}

Este parâmetro avalia a vizinhança magnética e portanto eletrônica de átomos em moléculas. Se o conjunto de base influencia o cálculo em compostos "aglomerados", espera-se uma maior concordância dos $\partial$ dos compostos-gaiola com os $\partial$ experimentais. Foram feitos cálculos de RMN utilizando o método $\mathrm{HF} / 6-31+\mathrm{G}^{* *}$ e geometria $\mathrm{pBP} / \mathrm{DN}^{* *}$ (Tabela 6). Também estão mostrados os resultados experimentais [Yates e Switlak, 1990; Cadd et al.,1993]. 
Tabela 8. Deslocamentos químicos de $\mathrm{RMN}$ de ${ }^{1} \mathrm{H}$ e de ${ }^{13} \mathrm{C}$ calculados por $\mathrm{HF} / 6-31+\mathrm{G}^{*}$ sobre a geometria pBP/DN** e determinados experimentalmente para as moléculas S11 [Yates e Switlak, 1990] e S12 [Cadd et al.,1993] (ppm). Os resultados são em relação tetrametilsilano. Também são mostrados os desvios percentuais entre o experimental e o calculado.

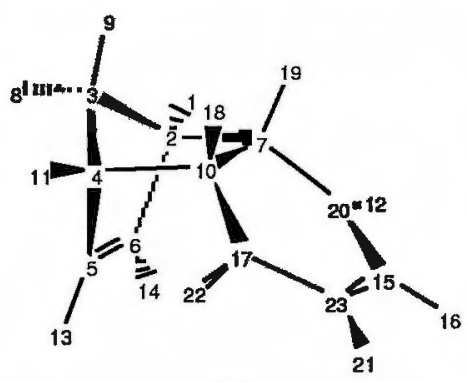

S11

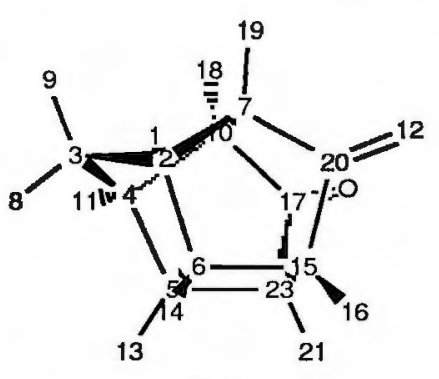

S12

\begin{tabular}{c|c|c|c|c|c|c|c|c}
\hline Átomo & S11 & S11 & S11 & S11 & S12 & S12 & S12 & S12 \\
\hline & calc. & exp. & er./ppm & erro $/ \%$ & calc. & exp. & er./ppm. & erro /\% \\
\hline $\mathrm{C}(2)$ & 43,18 & 48,3 & 5,1 & 10,6 & 40,36 & 44,7 & 4,3 & 9,7 \\
\hline $\mathrm{C}(3)$ & 45,41 & 48,6 & 3,2 & 6,6 & 38,34 & 40,5 & 2,2 & 5,3 \\
\hline $\mathrm{C}(4)$ & 44,03 & 48,7 & 4,7 & 9,6 & 49,60 & 54,7 & 5,1 & 9,3 \\
\hline $\mathrm{C}(5)$ & 141,99 & 133,1 & 8,9 & 6,7 & 38,23 & 38,8 & 0,6 & 1,5 \\
\hline $\mathrm{C}(15)$ & 146,75 & 141,9 & 4,9 & 3,4 & 43,54 & 43,8 & 0,3 & 0,6 \\
\hline $\mathrm{C}(17)$ & 203,96 & 199,2 & 4,8 & 2,4 & 211,75 & 212,1 & 0,4 & 0,2 \\
\hline média & & & 5,3 & 6,5 & & & 2,1 & 4,4 \\
\hline $\mathrm{H}(1)$ & 2,21 & 3,52 & 1,3 & 37,2 & 1,39 & 2,95 & 1,6 & 52,9 \\
\hline $\mathrm{H}(8)$ & 0,64 & 1,48 & 0,8 & 56,9 & 0,89 & 1,90 & 1,0 & 53,3 \\
\hline $\mathrm{H}(9)$ & 0,54 & 1,48 & 0,9 & 63,3 & 1,00 & 2,05 & 1,1 & 51,4 \\
\hline $\mathrm{H}(13)$ & 4,57 & 6,02 & 1,5 & 24,1 & 1,57 & 3,18 & 1,6 & 50,6 \\
\hline $\mathrm{H}(16)$ & 4,49 & 6,52 & 2,0 & 31,2 & 1,05 & 2,81 & 1,8 & 62,5 \\
\hline $\mathrm{H}(18)$ & 1,52 & 3,28 & 1,8 & 53,6 & 1,09 & 2,71 & 1,6 & 59,8 \\
\hline média & & & 1,4 & 44,4 & & & 1,4 & 55,1 \\
\hline
\end{tabular}

Os desvios percentuais entre os valores calculados e determinados para o ${ }^{13} \mathrm{C}$ confirmam a hipotese de que os cálculos de moléculas-gaiola são mais sensíveis ao tamanho da base, e que para os abertos, a conjugação exige um método que leve em conta a correlação eletrônica. O erro para a molécula-gaiola é ca. de $4 \%$, e os deslocamentos químicos calculados para a espécie aberta desvia-se em $\mathrm{ca}$. de $6 \%$ dos valores experimentais. Estes resultados confirmam as suspeitas, levantadas nos resultados de calor de combustão, de que as moléculas-gaiola têm as suas interações interatômicas entre átomos não-ligados melhor avalia- 
das do que as moléculas abertas, nas quais os átomos não ligados estão mais afastados.

Nota-se uma maior dispersão dos resultados para ${ }^{1} \mathrm{HRMN}$ comparados $c 0 m{ }^{13} \mathrm{CRMN}$. Os resultados de ressonância protônica não deveriam mostrar sensibilidade à base de cálculo já que, mesmo nos compostos-gaiola, os hidrogênios estão mais distantes entre si que os carbonos, e que provavemente necessitariam de bases mais abrangentes que a utilizada. Isto também pode ser observado na diferença muito maior em relação aos valores experimentais. Como estes átomos são calculados com menor exatidão, é razoável que as diferenças sejam maiores.

Os dados da Tabela 8 foram plotados em gráficos do experimental em função do calculado, para observar a correlação dos dados (Figuras 13, 14, 15 e16)

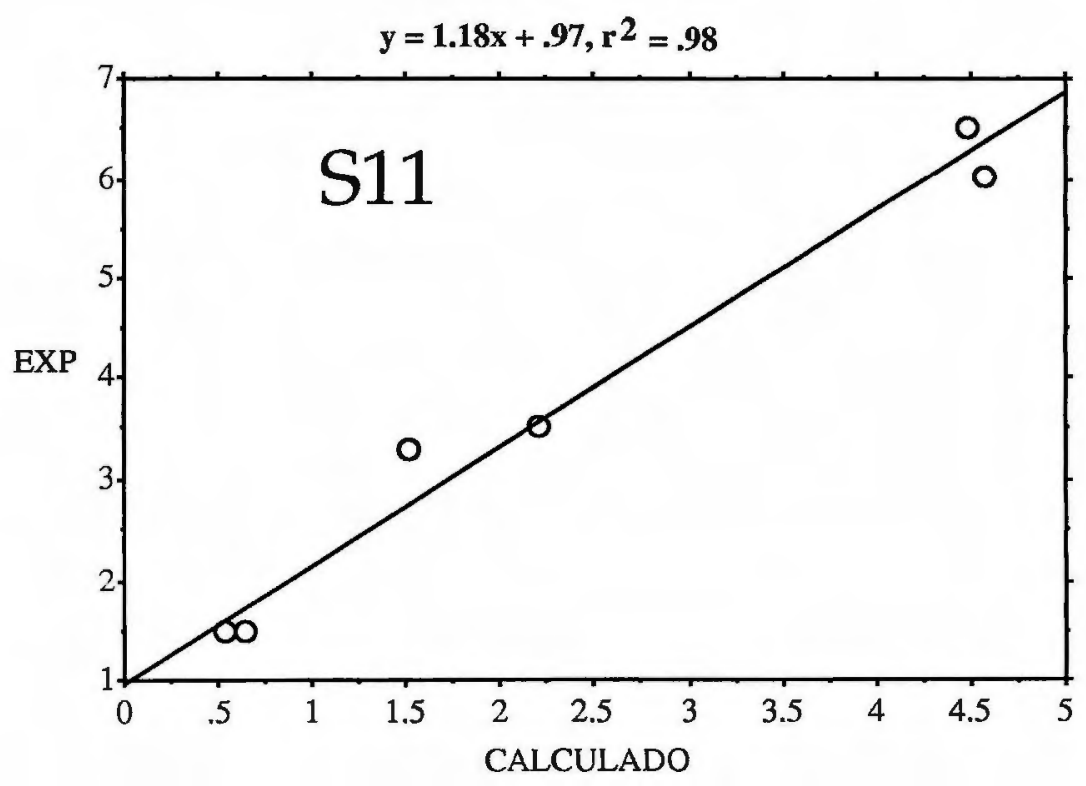

Figura 13. Gráfico dos deslocamentos químicos de ${ }^{1} \mathrm{HRMN}$ determinados para molécula S11 em função dos calculados (ppm), com regressão linear. 


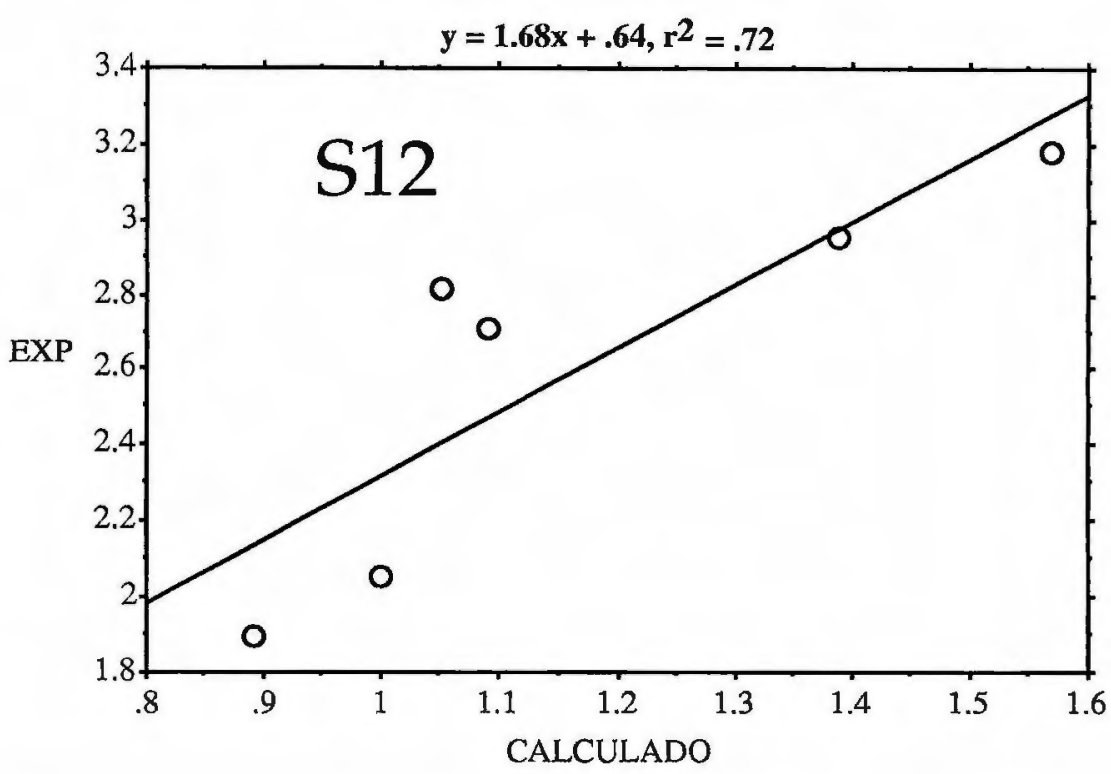

Figura 14. Gráfico dos deslocamentos químicos de ${ }^{1} \mathrm{HRMN}$ determinados para molécula $\mathrm{S} 12$ em função dos calculados (ppm), com regressão linear.

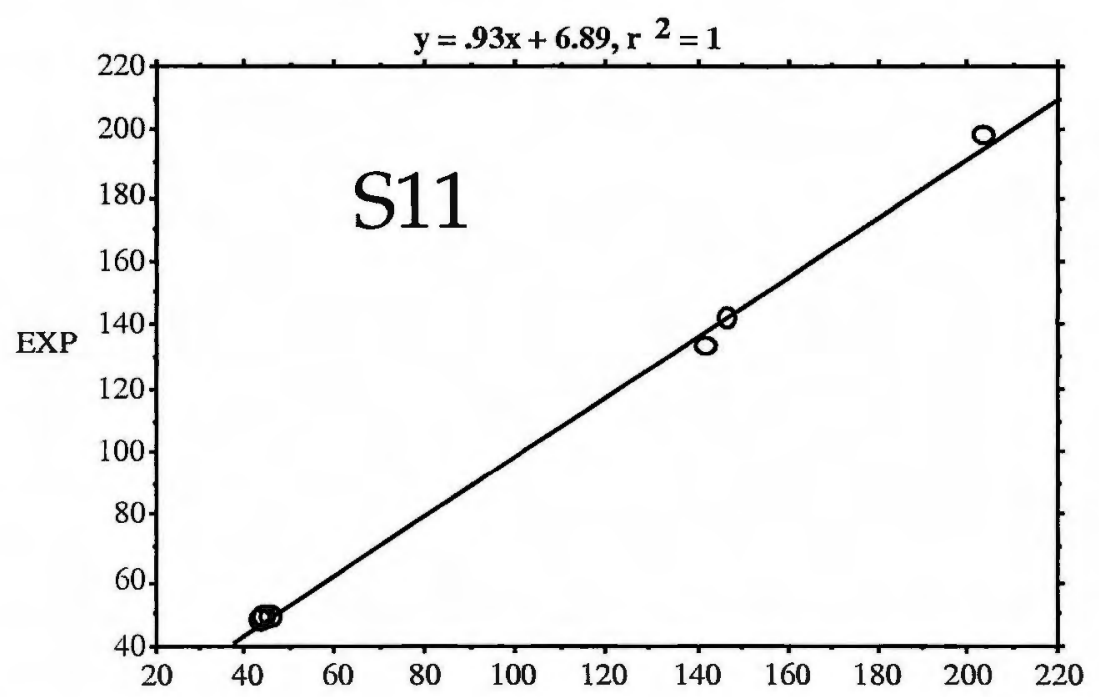

Figura 15. Gráfico dos deslocamentos químicos de ${ }^{13} \mathrm{C}$ RMN determinados para molécula S11 em função. dos calculados (ppm), com regressão linear. 


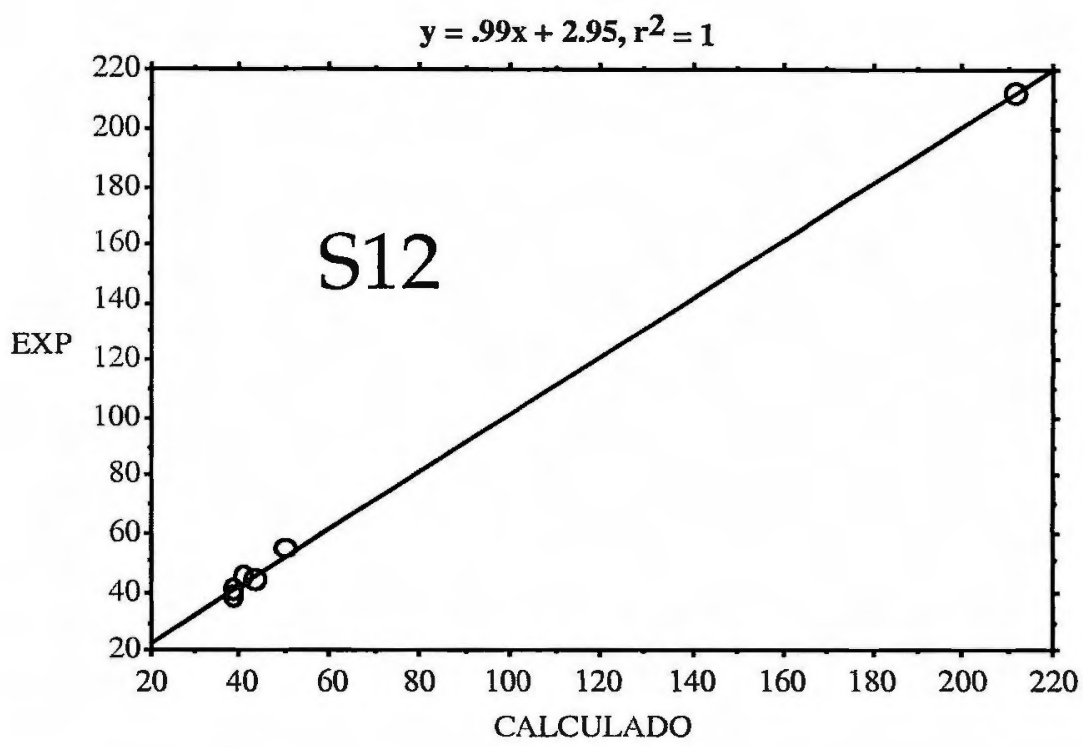

Figura 16. Gráfico dos deslocamentos químicos de ${ }^{13} \mathrm{C}$ RMN determinados para molécula $S 11$ em função dos calculados (ppm), com regressão linear.

Os resultados mostram que os deslocamentos experimentais e calculados para o carbono são mais correlacionados do que os para o hidrogênio. Isto indica que as conclusões tiradas acima com base nos desvios percentuais são razoáveis. Os erros para o hidrogênio são percentualmente grandes, e além disso os resultados calculado e experimental não estão muito bem correlacionados, sobretudo para a gaiola S12. Para o caso dos deslocamentos químicos de ${ }^{13} \mathrm{C}$, os dados estão muito bem correlacionados, apesar de não ser possível estabelecer um fator de correção multiplicativo para os valores calculados pela equação da reta de regressão.

Ou seja, a hipotese da melhor modelagem de moléculas-gaiola a partir dos desvios percentuais de RMN de carbono são endossadas pela boa correlação dos resultados. Para o RMN protônico, a correlação mostra que a decisão de desconsiderar estes resultados como indicativos de melhor ou pior modelagem foi acertada. Estes resultados são mais um indicativo que as moléculas gaiola são melhor calculadas que as moléculas abertas. 


\section{v. Outros resultados da Literatura.}

A hipótese da melhor concordância de resultados de cálculo para moléculas compactas foi testada com outros resultados disponíveis na literatura. Em estudos envolvendo fulerenos de vinte carbonos [Prinzbach, 2000] pode ser encontrado apoio para a verificação desta hipotese. Nos isômeros de vinte átomos de carbono existem estruturas análogas às do estudo feito para as cetonas de Cookson: uma molécula compacta análoga à cetona-gaiola, um policiclo que possui ligaçôes múltiplas conjugadas e um anel com insaturaç̃es triplas alternadas. As duas últimas moléculas podem ser considerados análogos grosseiros das moléculas S11 e S21 (Figura 13).

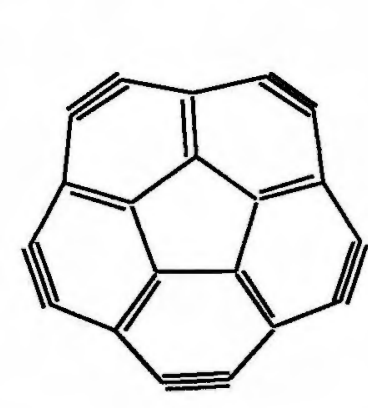

Tigela

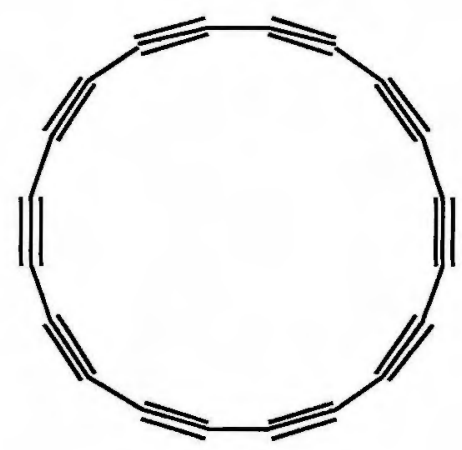

Anel

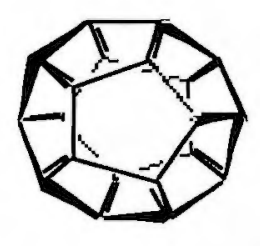

Gaiola

Figura 17. Estruturas isômeras do $C_{20}$.

A relação entre as cetonas de Cookson e as formas alotrópicas de vinte carbonos é a de que moléculas com elétrons conjugados e moléculas compactas devem possuir interações bastante diferentes, que a princípio não podem ser avaliadas de maneira identica em métodos de cálculo diferentes. Isto deve se refletir no valor das energias calculadas. Apesar da molécula-gaiola possuir conjugação eletrônica, a curvatura da molécula implica numa diferença grande para a conjugação dos isômeros tigela e anel. A situação é semelhante para as cetonas-gaiola de Cookson, cujo isômero aberto possui conjugação e o fechado possui interações através de ligações simples. Um caso conhecido das particularidades de se calcular a energia de moléculas cíclicas é o uso de funções de polarização, que são indicadas para estes sistémas. [Simons, 1991; Head-Gordon, 1996]. No caso dos aglomerados de carbono mostrados na Figura11, não se consegue determinar qual das três conformações imaginadas seria a mais estável [Murphy e Friesner, 1998] (Tabela 9). 
Tabela 9. Diferenças energéticas entre os isômeros do $C_{20}$ [Murphy e Friesner, 1998], referenciados aos valores do isômero "tigela".

\begin{tabular}{l|c|c|c}
\hline \multicolumn{1}{c|}{ método } & tigela & anel & gaiola \\
\hline HF/cc-pVTZ(++) & 0 & $-32,6$ & 69,2 \\
\hline LMP2/cc-pVTZ(-f) & 0 & 21,9 & 61,6 \\
\hline LMP2/cc-pVTZ(++/3d1f) & 0 & 39,3 & 42,6 \\
\hline LMP2/cc-pVTZ(++/3d2f) & 0 & 41,7 & 32,8 \\
\hline GVB/cc-pVTZ(-f) & 0 & $-5,0$ & 99,1 \\
\hline GVB-LMP2/cc-pVTZ(-f) & 0 & 23,8 & 63,0 \\
\hline J1/cc-pVTZ(++/3d1f) & 0 & 24,4 & 60,7 \\
\hline J1/cc-pVTZ(++/3d2f) & 0 & 26,8 & 51,0 \\
\hline QMC & 0 & $23,0 \pm 4,6$ & $52,0 \pm 4,6$ \\
\hline B3LYP/cc-pVTZ(-f) & 0 & $-5,8$ & 37,4 \\
\hline BLYP/cc-pVTZ(-f) & 0 & $-20,9$ & 45,7 \\
\hline
\end{tabular}

Os resultados mostram que o isômero mais estável muda de acordo com o método de cálculo usado. Admitindo-se o método de Monte Carlo Quântico (QMC) como o mais exato, pode ser feita uma comparação da concordância dos demais métodos com o QMC através da análise da dispersão dos resultados (Figuras 18 e 19). 


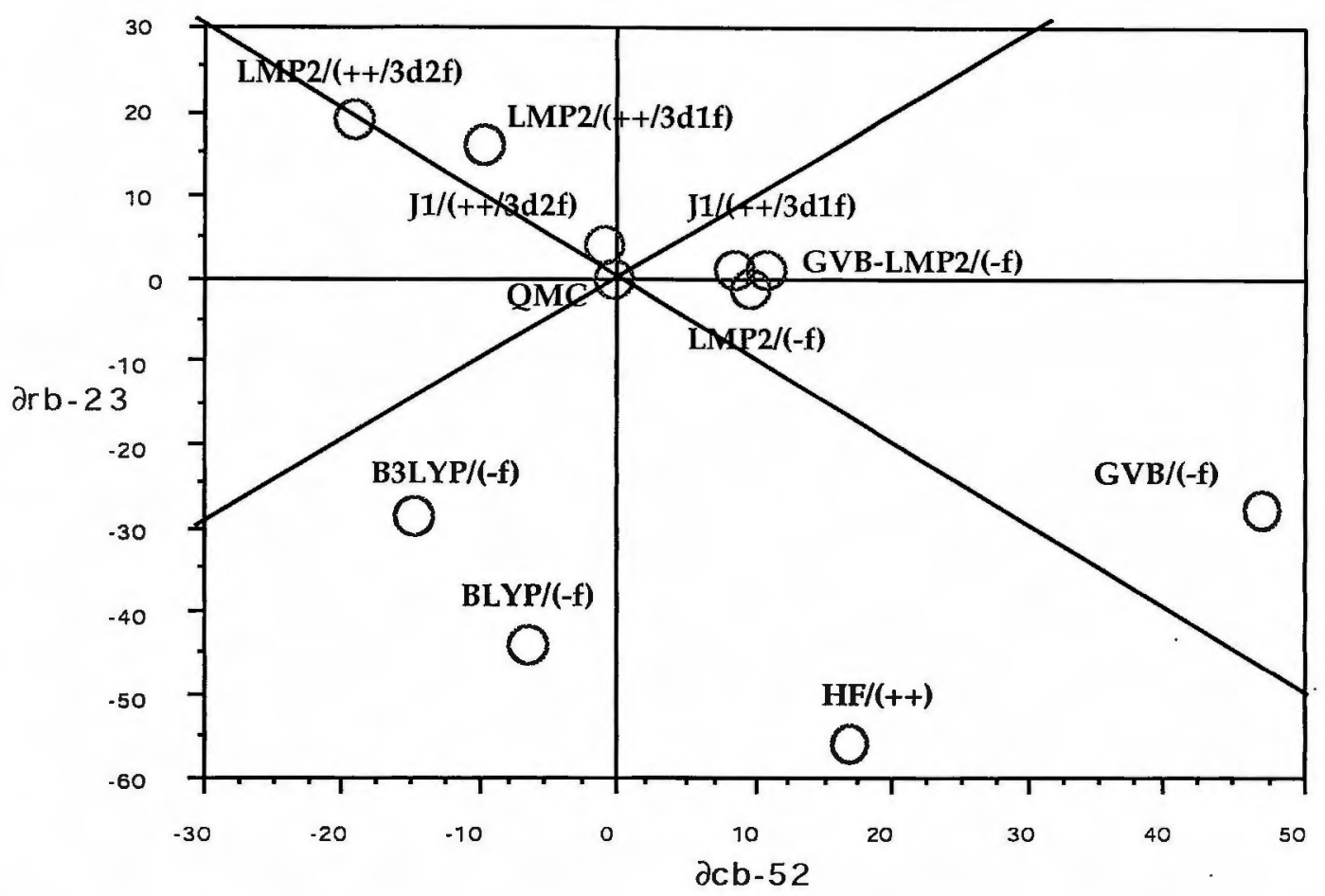

Figura 18. Diferença entre os diferentes métodos e o QMC. Anel (ordenada) e gaiola (abcissa) $/ \mathrm{kcal}^{-} \mathrm{mol}^{-1}$.

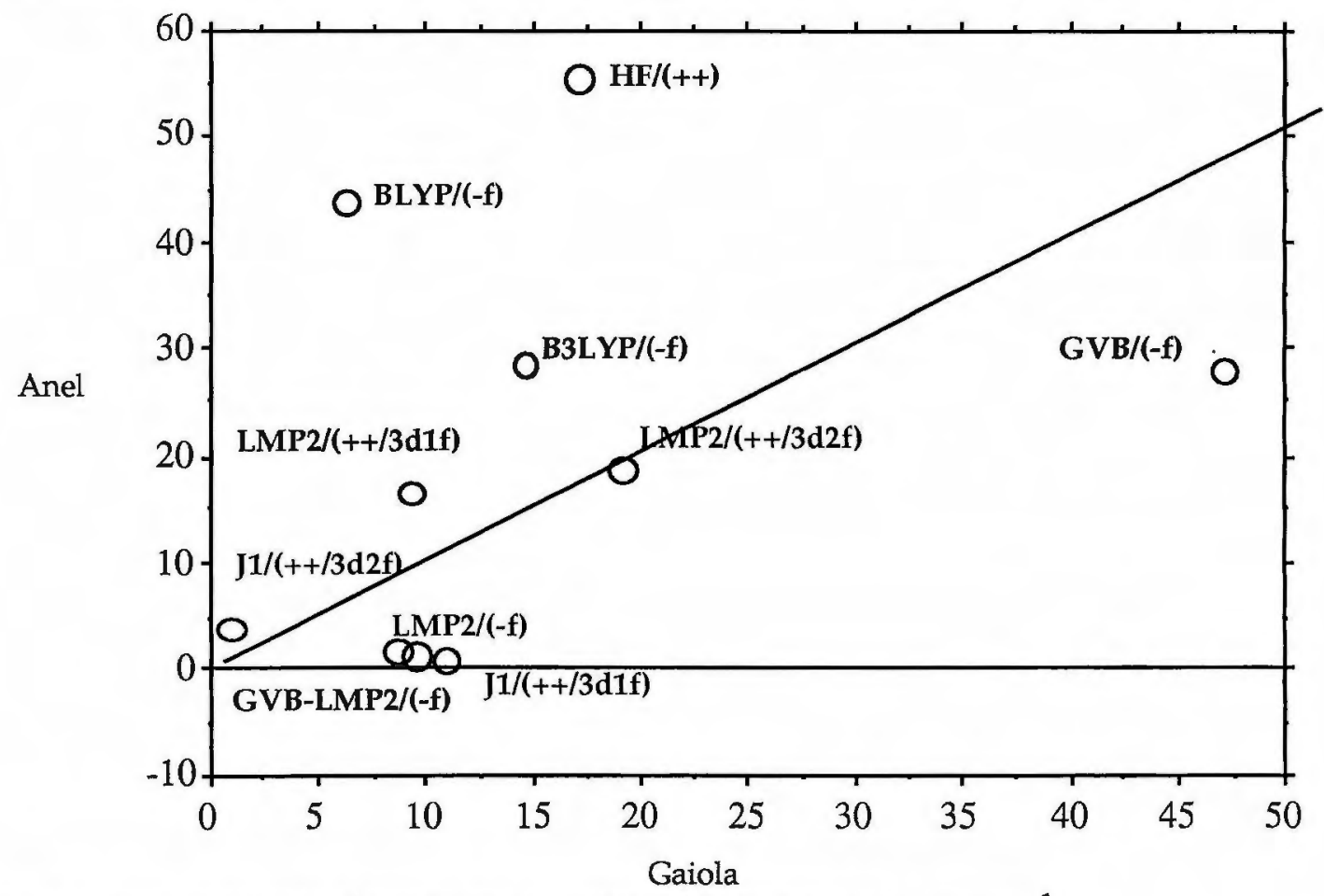

Figura 19. Diferença em módulo entre os diferentes métodos e o $\mathrm{QMC} / \mathrm{kcalmol}^{-1}$. 
Como todos os cálculos utilizam a base cc-pVTZ, e as diferenças entre as bases estão nas funções difusas e de polarização, foi feita a suposição de que as diferenças estão centradas nos métodos. Isto é, não se pode afirmar que o resultado seja muito influenciado pela avaliação diferente de interações nãoligantes, pois as bases foram consideradas abrangentes o suficiente para diminuir a influência desta possibilidade. A concordância em relação ao Monte Carlo Quântico $(\mathrm{QMC})$ é vista pela distância em relação à̀ retas que se cruzam na origem so sistema de coordenadas, que é o resultado do QMC.

Dos diagramas apresentados nas Figuras 18 e 19, o que pode inicialmente ser visto é a falta de concordância dos métodos GVB, HF, BLYP e B3LYP em relação ao valor do QMC. A análise será feita sobre a não concordância destes métodos em relação ao Monte Carlo Quântico. Estes resultados estão divididos em dois grupos. Num grupo está o método GVB, que é um método em que a correlação eletrônica é considerada, e cujo erro para a gaiola é maior do que o erro para o anel. No outro grupo estão os métodos HF, B3LYP e BLYP, cujos resultados estão mais afastados no caso do anel, e cujo tratamento da correlação é menos eficiente. Este agrupamento foi observado para o caso das moléculas de Cookson. Ou seja, pode ser concluído que moléculas com elétrons conjugados são realmente mais sensíveis a métodos de correlação, a ponto de criar uma diferença grande na concordância com valore ditos como exatos. Isso pode ser visto na melhor concordância dos métodos do outro grupo para a gaiola, o que indica que a correção feita pela correlação não foi adequada. Apesar da gaiola possuir também conjugação de orbitais, este efeito é menor do que no caso do anel, pois a curvatura acentuada da molécula gaiola desfavorece a deslocalização eletrônica, que é favorecida no caso do anel, por este ser plano.

No caso dos métodos de maior exatidão e menor dispersão, também podem ser observados dois grupos distintos, em que a concordância em para a gaiola e para o anel são diferentes. Isto pode ser visto na Figura 20, onde a reta de iclinação igual a 1 separa os métodos em dois grupos. Os pontos com maior erro para a gaiola que estão abaixo da reta, e os pontos onde há maior erro para o anel estão acima da reta. Na figura 19, a proximidade da reta de inclinação igual a 1 indica os métodos que são mais isentos, ou seja, os métodos que cometem erros parecidos para ambas as moléculas. Neste caso, o método B3LYP é o que mais se aproxima desta característica. Os métodos mais próximos da reta de inclinação -1 cometem erro positivo para um dos caso e negativo para o outro. Neste aspecto, os métodos que estão nesta situação são os de maior inexatidão. A concordância nos resultados obtidos com métodos de precisão sofre ainda $o$ efeito do conjunto base, de modo que a concordância melhor para o anel ou para a gaiola varia para um mesmo método (Figura 20). Para explicar tal comportamento, seria necessário um estudo específico do efeito da base em tais moléculas, o que não existe na literatura. Mesmo assim, os resultados mostram que as hipoteses levantadas para o caso das cetonas de Cookson com base nos estudos de isomerização e combustão são observados, ainda que qualitativamente, em outro sistema relacionado.

Uma outra maneira de avaliar a importância de interações não-ligantes e o seu efeito no resultado de cálculos de compostos-gaiola foi feito em estudos sobre interações de carbonilas não-ligadas em moléculas semelhantes às cetonas de Cookson. Resultados experimentais levam à conclusão que as inter- 
ações entre as carbonilas são a maior parcela do total [Marchand, 1987; Chow, 1989]. Com métodos teóricos, estas interações são avaliadas de três formas diferentes [Jimenez,1999]. Primeiramente, utilizando o método de Benson de equivalentes de grupo [Benson, 1976], e depois pelo método de Ibrahim [Ibrahim,1990] e finalmente pela reação isodésmica abaixo:

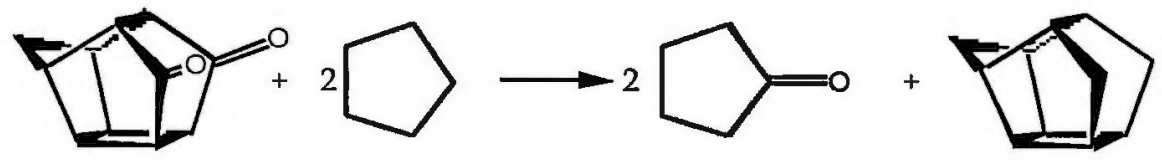

Calculou-se o calor de formação do composto S12 por equivalentes de grupo, que não considera efeitos de tensão e efeitos de átomos não-ligados, e deste valor foi subtraído o valor experimental que inclui estas parcelas da energia, obtendo $c a$. de $33 \mathrm{~kJ} \cdot \mathrm{mol}^{-1}$. O valor de $34.4 \mathrm{~kJ} \mathrm{~mol}^{-1}$ foi obtido pelo método de Ibrahim, que utiliza a equação:

$$
\Delta H_{m}(\text { tensao })=\sum N_{i} X_{i}-\Delta H_{m}(\text { ligacao })_{\text {expt }}
$$

Com a reação isodésmica, Jimenez fez um estudo do valor da energia de interação das carbonilas da S12. Nesta dissertação, isto foi feito supondo-se uma energia de tensão e interação de hidrogênios na gaiola sem carbonilas igual a 2t, e uma energia de interação no composto gaiola igual a $t+c$, tal que cé a energia de interação das carbonilas. Para encontrar os valores de $2 t$ e de $t+c$, foram calculadas entalpias de formação e combustão (Tabela 10).

Tabela 10. Entalpias de formação e de combustão determinadas experimentalmente, por cálculos $\mathrm{pBP} / \mathrm{DN}^{* *} / / \mathrm{pBP} / \mathrm{DN}^{* *}$ e por equivalente de grupo.

\begin{tabular}{l|c|c}
\hline \multicolumn{1}{|c|}{ Entalpias / kcal mol ${ }^{-1}$} & \\
\hline$\Delta \mathrm{H}$ (formação - calorimetria) & 17,13 & $-27,14$ \\
\hline$\Delta \mathrm{H}$ (formação - Benson) & $-29,98$ & $-82,08$ \\
\hline \hline $\mathrm{H}$ (combustão - Benson) & $-1414,30$ & $-1246,42$ \\
\hline$\Delta \mathrm{H}$ (combustão - calorimetria) & $-1515,81$ & $-1328,77$ \\
\hline$\Delta \mathrm{H}$ (combustão - lei de Hess - exp.) & $-1461,23$ & $-1301,36$ \\
\hline$\Delta \mathrm{H}$ (combustão - pBP/DN*) & $-1378,35$ & $-1233,02$ \\
\hline
\end{tabular}

Como os valores obtidos pelo método de equivalentes de grupo não contém as interações nãoligantes e nem as tensões de anel, este valor pode ser usado para encontrar os valores de $2 t$ e $t+c$. Para fazer isto, calcula-se a diferença dos resultados da tabela 8 para uma mesma molécula em relação ao valor 
calculado por Benson (que não inclui interaçס̃es) (Tabela 11).

Tabela 11. Cálculo da tensão estrutural ( $\mathrm{t}$ ) e da interação entre as carbonilas (c) $/ \mathrm{kcal} \mathrm{mol}^{-1}$.

\begin{tabular}{l|c|c|c|c}
\hline \multicolumn{1}{c|}{$\Delta(\Delta \mathrm{H})$} & $2 \mathrm{t}$ & $\mathrm{t}+\mathrm{c}$ & $\mathrm{t}$ & $\mathrm{c}$ \\
\hline Formação: Hess - Benson & 47.11 & 54.95 & 23.55 & -31.39 \\
\hline Combustão: Hess - Benson & -46.93 & -54.94 & -23.47 & -31.47 \\
\hline Combustão: Calorimetria - Benson & -101.51 & -82.35 & -50.76 & -31.59 \\
\hline Combustão: Calorimetria - Hess & -54.58 & -27.41 & -27.29 & -0.12 \\
\hline Combustão: pBP/DN** - Benson & 35.95 & 13.40 & 17.97 & -4.57 \\
\hline Combustão: Hess - DFT & -82.88 & -68.34 & -41.44 & -26.90 \\
\hline Combustão: Calorimetria - DFT & -137.46 & -95.75 & -68.73 & -27.02 \\
\hline
\end{tabular}

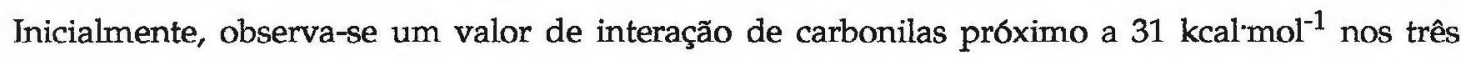
resultados iniciais. $O$ resultado seguinte, em que os valores experimentais são comparados, o valor de c'é aproximadamente zero. Isto é sinal de que ambos os resultados incluem a interação das carbonilas em extensão parecida e que o método proposto para calcular tais interações não é incorreto, apresar das entalpias de combustão terem valores bastante diferentes.

A diferença entre os valores calculados por equivalente de grupo e por $\mathrm{pBP} / \mathrm{DN}^{* *}$, mostra que o

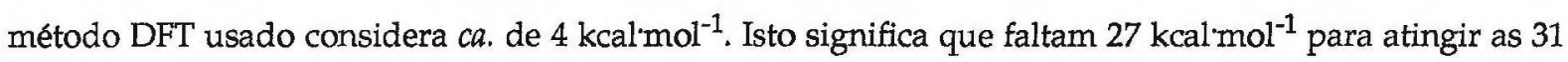
$\mathrm{kcal}^{\mathrm{mol}} \mathrm{l}^{-1}$ de interação das carbonilas, que é o resultado obtido pela diferença ente os métodos experimentais e o DFT. Este resultado indica que o método de cálculo $\mathrm{pBP} / \mathrm{DN}^{* *}$ só atinge uma extensão relativamente pequena da interação entre as carbonilas, e mesmo assim este valor é responsável pelas diferenças observadas. Este resultado é interessante pois indica que este método pode ser usado para calcular a fração da energia de correlação que um método de cálculo pode avaliar.

\section{vi. Fase condensada}

O método semi-empírico combina rapidez e precisão aceitáveis para estudar o fenômeno da solvatação. Apesar da inexatidão que provavelmente afeta as geometrias otimizadas, a alteração das distâncias interatômicas de acordo com a variação dos parâmetros do solvente pode ser utilizada de maneira satisfatória para se compreender o efeito do meio sobre a estrutura molecular. Isto é, de acordo com a tendência de aproximação ou afastamento verificada numa distância interatômica, ao alterar-se um parâmetro como por exemplo a constante dielétrica do meio, pode-se inferir o comportamento da molécula em fase solvatada e identificar quais as interações mais influentes neste comportamento. Por esta 
razão, foram calculadas as energias livres de solvatação num número grande de solventes. Dessa forma, espera-se observar com clareza o efeito do solvente na estrutura e as implicações energéticas desta mudança estrutural. Os solventes que abrangem uma faixa larga de parâmetros de solvatação usados no método usado no AMSOL 6.6. Estes parâmetros são a constante dielétrica, a tensão superficial, o índice de refração e os caráteres prótico e aprótico. Neste trabalho foi usada a hamiltoniana PM3, que contém uma parametrização otimizada. Para calcular a energia livre de solvatação otimiza-se a geometria duas vezes: uma na fase gasosa e outra no interior da cavidade que simula o solvente. O método calcula a energia livre de Gibbs das estruturas em cada um destes meios e a energia livre de solvatação pela diferença entre elas. As diferenças de energia livre de solvatação entre as moléculas das séries foram calculadas e estão dispostas em ordem decrescente de constante dielétrica do solvente correspondente (Tabelas 12 e 13).

Tabela 12. Diferenças de energia livre de solvatação calculada para as moléculas da série I / $\mathrm{kcalmol}^{-1}$.

\begin{tabular}{l|l|l|l}
\hline & & \\
\hline Série I
\end{tabular}

(*) Solventes em que a otimização da geometria S11a convergiu para a conformação S11b. 
Tabela 13. Energia livre de solvatação das moléculas da série II / $\mathrm{kcalmol}^{-1}$ :

\begin{tabular}{l|l|l|l}
\hline & & $-1,71$ & \\
\hline água & $-1,68$ & $-0,64$ & 2,14 \\
\hline acetonitrila & $-0,64$ & $-0,78$ & 3,21 \\
\hline metanol & $-1,11$ & $-0,70$ & 3,01 \\
\hline etanol & $-1,04$ & $-0,65$ & 3,01 \\
\hline propanol & $-0,99$ & $-0,62$ & 2,99 \\
\hline butanol & $-0,95$ & $-0,52$ & 3,05 \\
\hline metoxietanol & $-0,91$ & $-0,46$ & 2,77 \\
\hline octanol & $-0,77$ & $-0,01$ & 2,69 \\
\hline bromobenzeno & $-0,33$ & $-0,10$ & 2,41 \\
\hline cloroformio & $-0,36$ & 0,13 & 2,52 \\
\hline anisol & $-0,19$ & 0,52 & 1,95 \\
\hline benzeno & 0,26 & 0,48 & 1,88 \\
\hline tetraclorocarbono & 0,24 & 0,52 & 1,78 \\
\hline hexadecano & 0,29 & 0,52 & 1,76 \\
\hline ciclohexano & 0,30 & 0,53 & \\
\hline dodecano & 0,30 & & \\
\hline & 0 & & \\
\hline
\end{tabular}

Foram encontradas duas conformaçб̌es para S11 e S21, uma a menos que as encontradas na fase gasosa. Algoritmos semi-empíricos favorecem estruturas simétricas, e talvez por isto a estrutura com uma carbonila voltada para cada lado não tenha sido encontrada. Este fato explica o observado em S13, onde foi encontrada apenas a conformação simétrica, porém não encontrada com o método ab initio. Para S23 foi utilizada apenas a conformação mais estável da fase gasosa. Apesar desta estrutura não ser simétrica, como a diferença de energia é grande, o confôrmero simétrico não foi encontrado. Na série I, em quatro solventes pouco polares, a conformação S11b, em que as carbonilas estão "para baixo", foi sempre mantida

Os resultados mostram um efeito coerente da solvatação sobre as moléculas de ambas as séries. Nas isomerizações de S11 a S21 e de S12 a S22, nota-se que as gaiolas são melhor solvatadas à medida que o solvente torna-se mais polar. $\mathrm{O}$ valor negativo indica isto do $\Delta \mathrm{G}$. Em solventes pouco polares, nota-se 
pelo valor positivo da energia livre de solvatação que as espécies abertas são as melhor solvatadas.

Para a reação de isomerização de S13 e S23, o comportamento é o oposto do observadio na isomerização de S11 e S21. Aquelas espécies são melhor solvatadas que as gaiolas em qualquer meio, e a energia livre de solvatação se torna mais positiva com o aumento da polaridade do meio.

O efeito da solvatação na estrutura molecular foi avaliado com a medida de algumas distâncias interatômicas (Tabela 14).

Tabela 14. Média e variações máximas de algumas distâncias interatômicas das moléculas solvatadas / $̊$.

\begin{tabular}{|c|c|c|c|c|c|c|c|c|}
\hline $\begin{array}{l}\text { distância } \\
\text { e átomos }\end{array}$ & S11a & $\mathrm{S} 11 \mathrm{~b}$ & $\mathrm{~S} 12$ & $\mathrm{~S} 13$ & a & $1 b$ & $\mathrm{~S} 22$ & 23 \\
\hline $\begin{array}{l}\mathrm{C}(1)-\mathrm{C}(2) \\
\text { (variação) }\end{array}$ & $\begin{array}{c}2,264 \\
(0,001) \\
\end{array}$ & $\begin{array}{c}2,264 \\
(0,001) \\
\end{array}$ & $\begin{array}{c}2,277 \\
(0,001) \\
\end{array}$ & $\begin{array}{c}2,460 \\
(-0,003) \\
\end{array}$ & $\begin{array}{r}2,563 \\
(0,001) \\
\end{array}$ & $\begin{array}{c}2,559 \\
(0,000) \\
\end{array}$ & $\begin{array}{c}2,589 \\
(0,002) \\
\end{array}$ & $\begin{array}{c}3,025 \\
(-0,002) \\
\end{array}$ \\
\hline $\begin{array}{l}\text { carbonilas } \\
\text { (variação) }\end{array}$ & $\begin{array}{c}2,923 \\
(-0,039)\end{array}$ & $\begin{array}{c}2,887 \\
(-0,031)\end{array}$ & $\begin{array}{c}2,536 \\
(-0,021)\end{array}$ & $\begin{array}{c}2,927 \\
(-0,016)\end{array}$ & $\begin{array}{c}2,852 \\
(-0,035)\end{array}$ & $\begin{array}{c}2,824 \\
(-0,037)\end{array}$ & $\begin{array}{c}2,489 \\
(-0,019)\end{array}$ & $\begin{array}{c}3,040 \\
(-0,012)\end{array}$ \\
\hline $\begin{array}{l}\text { oxigênios } \\
\text { (variação) }\end{array}$ & $\begin{array}{c}5,309 \\
(-0,098)\end{array}$ & $\begin{array}{c}5,186 \\
(-0,125)\end{array}$ & $\begin{array}{c}3,835 \\
(-0,064)\end{array}$ & $\begin{array}{c}3,085 \\
(0,024)\end{array}$ & $\begin{array}{c}5,112 \\
(-0,092)\end{array}$ & $\begin{array}{c}5,005 \\
(-0,102)\end{array}$ & $\begin{array}{c}3,734 \\
(-0,058)\end{array}$ & $\begin{array}{c}3,215 \\
(-0,065)\end{array}$ \\
\hline
\end{tabular}

As pequenas variações observadas nas distâncias interatômicas permitem concluir que a mudança do solvente pouco altera as estruturas moleculares, o que significa que as estruturas são bastante rígidas. A distância entre os carbonos 1 e 2 sofre a maior alteração, de $-0,003 \AA$, na molécula de S13. Por outro lado, há uma tendência de aproximação entre as carbonilas e dos seus oxigênios, ao aumentar-se a polaridade do solvente. Isso pode ser explicado pela tendência dos vetores de momento de dipolo induzidos por cada carbonila alinharem-se para potencializar a polaridade da molécula, quando esta encontra-se num meio polar. A soma vetorial máxima ocorre quando os vetores possuem mesma direção e sentido, e como as componentes deste vetor apontam para o átomo de oxigênio em cada carbonila, a aproximação das carbonilas favorece $o$ alinhamento destes vetores, o que esclarece a tendência observada.

Todas as moléculas estudadas sofrem alteraçōes muito semelhantes com o aumento da polaridade do meio. Isso significa que a solvatação as afeta de maneira parecida e que a inclusão do segundo carbono da ponte de metilenos não torna as moléculas da série II significativamente mais flexíveis que as da série I.

Os valores de distância interatômica mostram que a aproximação das carbonilas ocasionada pelo aumento da polaridade do meio é maior em S11 e S21 (ca. de 0,03 Å), um pouco menor em S12 e S22 (ca. de $0,02 \AA$ ) e a menor é vista em S13 e S23 (ca. de 0,015 Å). A aproximação das carbonilas e o aumento da sobreposição dos seus orbitais têm um efeito desestabilizador sobre as moléculas S12, S22, S13 e S23, causado pela repulsão dos elétrons destes orbitais. Assim, duas forças atuam nestas moléculas, à medida que a polaridade do meio aumenta: a tendência de aproximação das carbonilas causada pela tendência de maxi- 
mização do momento de dipolo e o aumento da repulsão intereletrônica gerado por esta aproximação. A situação de S11 e S21 é diferente, pois como não ocorre a sobreposição de orbitais numa escala significativa, o efeito desestabilizador é devido ao prejuízo na conjugação eletrônica das duplas ligações.

Das espécies consideradas, em S12 e S22 as carbonilas encontram-se mais próximas (ca. de 2,5 $\AA$ ), o que sugere que elas sejam as mais sensíveis à aproximação das carbonilas. Mesmo com tais grupos mais afastados (ca. de 2,9 A), e portanto menos sensíveis à aproximação, nas S11 e S21 a instabilização, causada pela perda da conjugação das duplas ligações, parece ser grande o suficiente para tornar estas moléculas mais instáveis que as gaiolas em solventes polares. Em S13 e em S23 os grupamentos carbonílicos estão mais afastados (ca. de 3,0 Å), e ainda ocorreu a menor aproximação dos mesmos. Assim, estas são as moléculas menos afetadas pela repulsão eletrostática dos orbitais das carbonilas à medida que o meio torna-se mais polar, o que explica o aumento da diferença energética em relação às gaiolas.

Uma maneira mais clara de visualizar os dados é plotar um gráfico da diferença de energia de solvatação em função de uma distância interatômica importante, como por exemplo a distância entre os oxigênios (Figuras 20 e 21).

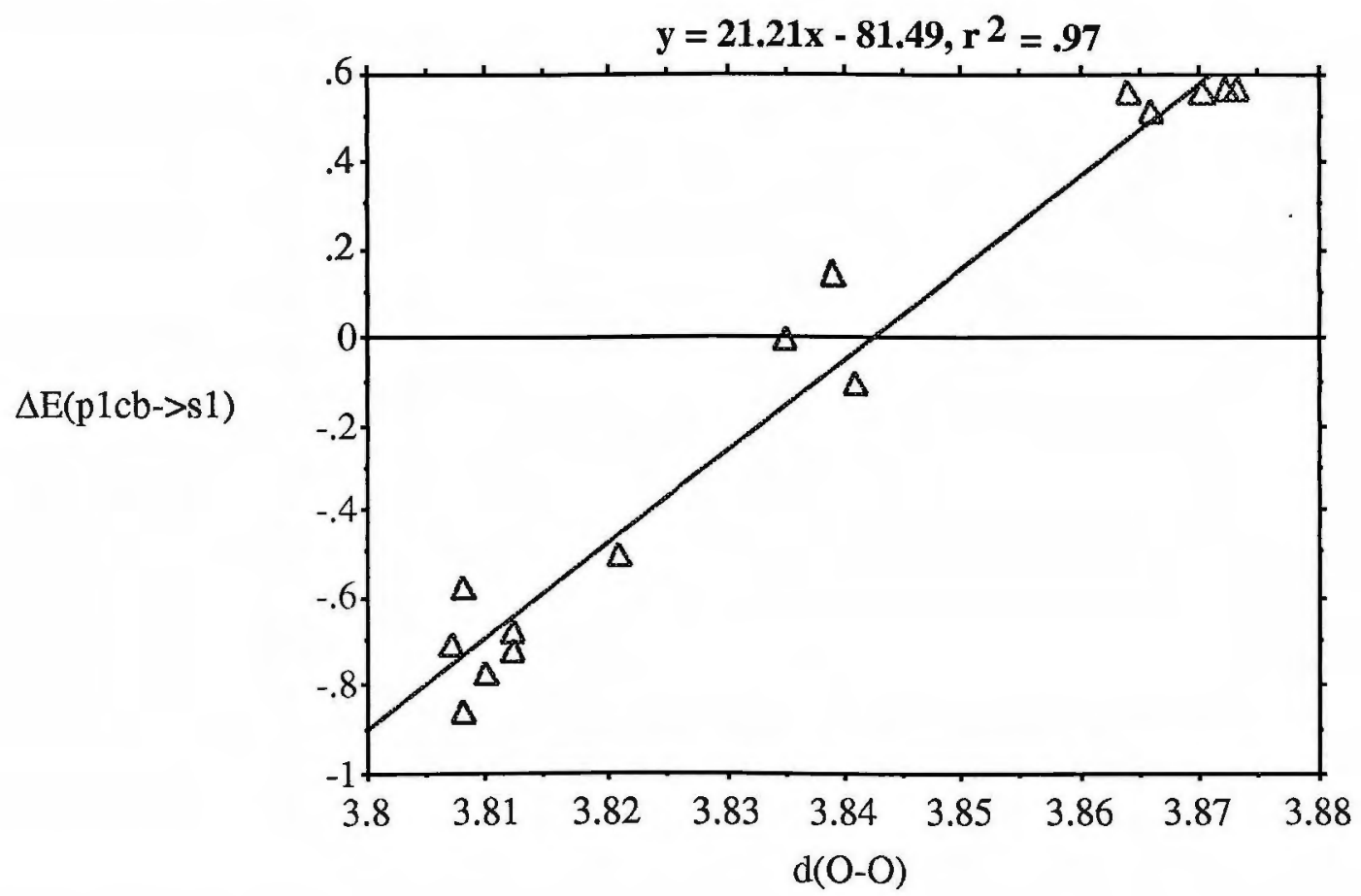

Figura 20. Graffico da diferença de energia $\left(\mathrm{kcal}^{-} \mathrm{mol}^{-1}\right)$ entre o isômero de S11 com as carbonilas para baịo e S12 em função da distância entre os oxigênios de S12 (A). 


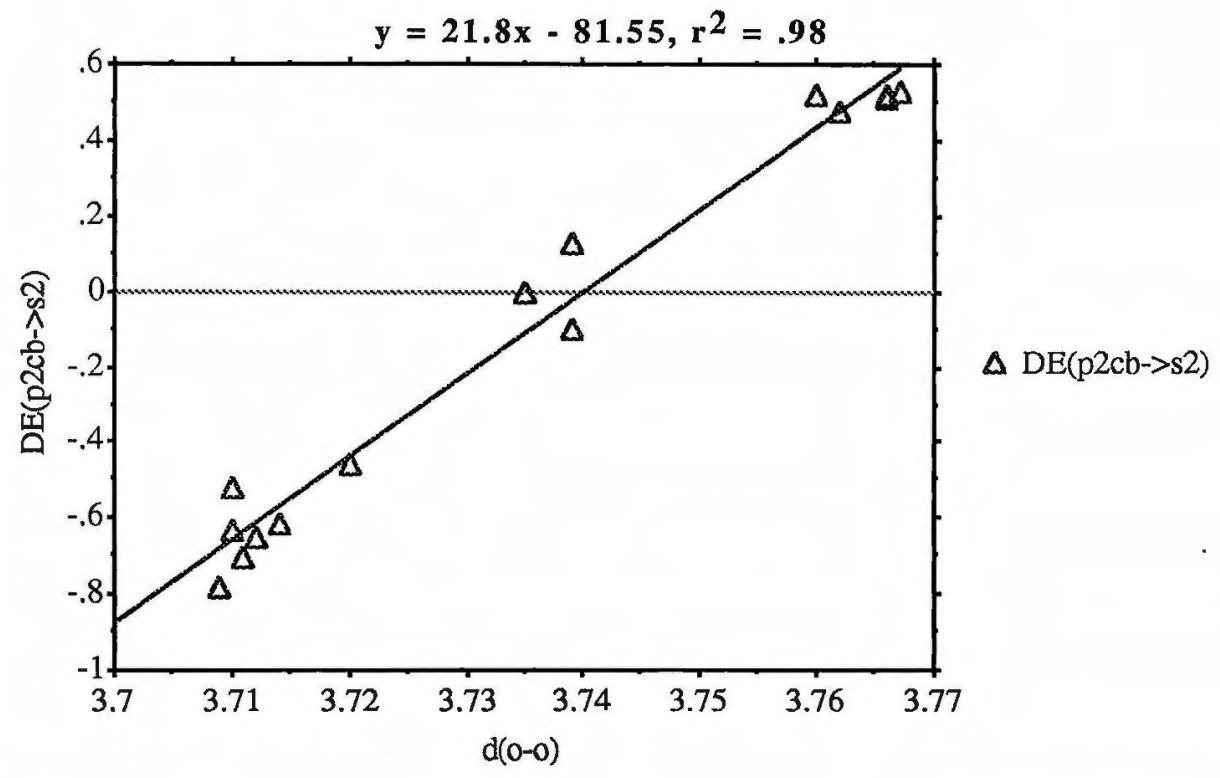

Figura 21. Gráfico da diferença de energia entre o isômero de $S 21 \mathrm{com}$ as carbonilas para baixo $\left(\mathrm{kcal}^{\cdot} \mathrm{mol}^{-1}\right)$ e S22 em função da distância entre os oxigênios de S22 ( $)$.

Dos resultados acima foi excluído o valor calculado para a água pois ele fica um pouco fora da reta da regressão linear, provavelmente devido ao caráter peculiar da água como solvente. Mesmo assim, os resultados confirmam o que foi apresentado na discussão anterior: que o aumento da polaridade do solvente favorece a solvatação das espécies fechadas, e causa uma diminuição da distância entre os oxigênios. 


\section{Conclusão}

Neste trabalho estudaram-se por computação os compostos conhecidos como cetonas de Cookson e seus precursores e derivados. A análise conformacional mostrou a existência de três conformações para S11 e S12 e duas conformações para S23. As cetonas-gaiola apresentaram uma única conformação.

Os resultados do calor de combustão calculados por CBS-4//HF-3-21G* mostram valores com desvio mínimo de ca. 7\% em relação aos resultados experimentais. $\mathrm{HF} / 3-21 \mathrm{G}^{*} / / \mathrm{HF} / 3-21 \mathrm{G}^{*}$ é o método menos adequado, cujos desvios em relação aos valores experimentais são $c a$. de $23 \%$. Como as moléculas de cada uma das séries são isômeros interconectados por uma adição [2+2], pode-se calcular o calor de isomerização deste processo. Nesse caso, o método CBS-4//HF/3-21G* é o que apresenta os resultados mais afastados dos valores experimentais. A explicação para este dado é o fato dos reagentes e produtos serem calculados com um erro significativamente diferente em ambos os casos. Os resultados do calor de combustão por CBS-4 das moléculas-reagente (S11 e S21), que são as abertas, têm um resultado ca. de 2,5 \% mais proximo do experimental do que as moléculas-gaiola. Como os valores de calor de combustão são da ordem de $1350 \mathrm{kcal} / \mathrm{mol}$, o desvio é suficiente para ocasionar um erro de $40 \mathrm{kcal} / \mathrm{mol} \mathrm{nos} \mathrm{calores} \mathrm{de}$ isomerização. Ou seja, como as moléculas têm suas estruturas modeladas de maneira diferente pelo método CBS-4, este é um método inadequado para comparar diretamente as energias das moleculas, apesar de ter o melhor desempenho para calores de combustão.

Nos valores de calores de combustão observa-se que as moléculas-gaiola (S12 e S22) têm resultados sistematicamente mais próximos dos valores experimentais do que as moléculas abertas (S11 e S21), se a base utilizada for pelo menos do tamanho da base 6-31G, independente do método utilizado. Se a base utilizada for do tipo 3-21G* observa-se o inverso: as moléculas abertas têm resultados mais concordantes com valores experimentais para o calor de combustão.

A explicação para este fenômeno é que as moléculas gaiola são estruturas mais compactas, onde os átomos encontram-se a distâncias menores, de modo que as interações não-ligantes têm uma importância maior no valor total da energia. As cetonas-gaiola de Cookson apresentam duas carbonilas numa posição interagente a uma distância curta, o que significa que esta interação deve ter uma contribuição alta no resultado final. A não consideração desta interação e de outras menos importantes causou o observado nos resultados feitos em bases $3-21 \mathrm{G}^{*}$, em que as moléculas abertas ficam com resultados mais próximos do experimental.

O fato do uso da base 6-31G ou maiores não tornar as diferenças iguais ou com uma concordância aleatoriamente próxima do experimental mostra que as bases usadas possivelmente não são grandes o suficiente para que as interações não-ligantes das moléculas abertas sejam consideradas de maneira idêntica em moléculas abertas e fechadas. A razão disto é o fato das distâncias de átomos não ligados serem maiores do que no caso das gaiolas. Outra possível razão é a existência de ligações duplas conjugadas nas moléculas abertas. Nas gaiolas, este tipo de interação não existe. Neste aspecto, o uso da correlação 
eletrônica no método desempenha um papel importante, pois elétrons conjugados demandam um tratamento mais rogoroso da correlação.

As diferenças estruturais entre as moléculas-gaiola $\mathrm{e}$ as abertas, que causaram os erros sistemáticos observados nos calores de combustão, permitem a conclusão de que a estrutura tem um efeito importante no resultado de cálculos de modelagem molecular, e que a negligência deste defeito causa erros que não podem ser explicados. O cálculo de calores de formação pela técnica de reações isodésmicas, por exemplo, está sujeito a grandes erros se for feito em moléculas em que a estrutura possa ter influência na exatidão do resultado. Assim, além da comparação das moléculas de reação isodésmica, sugere-se estudar a concordância individual dos resultados com os de alguma outra técnica, para que se conclua se realmente o resultado é causado por efeito da estrutura ou por inadequação do modelo. Ou seja, a hipótese do cancelamento de erros sistemáticos em reações isodésmicas parece não ser válido para o caso de moléculas complexas.

Além dos calores de combustão, foram calculados os deslocamentos químicos de ressonância magnética nuclear das espécies S11 e S12. A melhor concordância dos resultados de carbono 13 com os resultados experimentais para os compostos-gaiola mostra que estas recebem um tratamento diferente das moléculas abertas. Os resultados de deslocamentos químicos de proton são o oposto do observado, mas deve ser considerado que a base não inclui nem funções difusas e nem de polarização para melhorar a descrição da vizinhança ao redor destes átomos. Assim, apesar da diferença percentual ser maior para as gaiolas, a diferença absoluta é de 1,4 ppm para ambos os casos, o que possibilita concluir que os resultados de RMN de prótons não são indicativos de melhor modelagem para nenhum dos casos. Isso também pode ser constatado pelo fato dos erros percentuis para os prótons serem da ordem de $50 \%$, e para o carbono as diferenças percentuais são da ordem de $5 \%$.

Resultados de cálculos para isômeros de formas alotrópicas de vinte carbonos indicam que as interaçסes através de ligações devem ter importância para a modelagem de moléculas complexas que possuem estruturas com interações de ligações duplas conjugadas. Estruturas com conjugação de ligaçōes duplas têm resultados diferentes dos obtidos por moléculas que possuem conjugação de ligaçôes triplas. Estes resultados são análogos aos obtidos para as cetonas de Cookson, cujas carbonilas interagem através de ligações simples, e as espécies abertas têm interações através de ligações duplas. Este resultado aponta para o fato da complexidade estrutural ter detalhes que precisam ser considerados ao fazer cálculos de estruturas moleculares e avaliar os seus resultados.

Os resultados de calor de isomerização mostram que o método e que a hipótese do cancelamento de erros na técnica de reações isodésmicas pode levar a avaliações indevidas dos métodos.

Os resultados de solvatação das moléculas mostram pequenas variações nas distâncias interatômicas, o que mostra que estas moléculas têm estruturas bastante rígidas, o que parece previsível pelo fato de tratarem-se de policiclos cuja análise conformacional mostrou possibilidades de alteração das estruturas muito pequenas. Assim, espera-se que reações que envolvam tais moléculas sejam pouco afetadas pela sol- 
vatação. Porém, os resultados mostram que estudos cinéticos podem mostrar diferenças grandes ao mudar o solvente no qual a reação é levada a cabo. Isso porque a interação das carbonilas tem um efeito importante pelo fato da sua interação aumentar o momento de dipolo da molécula, apesar do aumento da repulsão entre os carbonos carbonílicos que acompanha o aumento da constante dielétrica.

Como última conclusão deste trabalho, pode ser feita uma especulação sobre porque as moléculasgaiola são difícies de serem modeladas. Pode ser suposto que existe um outro modelo mais exato para descrever as interações destas moléculas. Como nestas substâncias as ligações encontram-se muito próximas, pode ser que a sua interação seja algum tipo de ressonância como a encontrada em compostos aromáticos. Analogamente aos compostos aromáticos, cuja ressonância é feita por elétrons de ligações múltiplas, para o caso de compostos gaiola as ligações simples também poderiam entrar em ressonância e causar algum tipo de interação que as estabilizaria e também poderia ser chamada de aromaticidade. A interação de grupos distantes de uma molécula através de ligações simples já é conhecida [Woodward e Hoffmann, 1969], de modo que a interação destas mesmas ligações para estabilizar a molécula pode não ser tão absurda, e neste caso seria necessário um outro modelo conceitual para explicar os fatos.

Os estudos iniciados nesta dissertação precisam de mais trabalho para testar a validade das suas conclusões, e dentre as possibilidades de estudos futuros, podem ser citadas algumas sugestões. A comparação dos resultados obtidos por CBS-4 com outros tipos de método do conjunto completo de funções de base (CBS-q, CBS-Q e CBS-APNO). O estudo deste sistema com estas metodologias pode revelar se, à medida que o método de cálculo torna-se mais rigoroso as diferenças relativas em relação a valores experimentais tende para um patamar-limite de erro. Outros tipos de moléculas compactas poderiam ser estudados e comparados com isômeros. As suas diferenças experimentais poderiam ser comparadas com as suas diferenças calculadas de modo que o estudo de estruturas complexas e das suas interações internas poderia ser aprofundado.

Outro estudo importante é a determinação experimental e o cálculo dos deslocamentos químicọs de RMN das moléculas da série II. O cálculo do calor de combustão de S13 e S23 também acrescentariam um parâmetro de comparação importante para as molécula-gaiola e aberta, pois neste caso a estrutura comparada com a estrutura fechada é diferente, o que permite a comparação segundo outro ponto de vista.

Estudos das espécies solvatadas também são desejáveis. Sobretudo o efeito do solvente na velocidade dos processos. Os resultados aqui apresentados necessitam da comparação com o experimento para dizer se os resultados e conclusões obtidas procedem e também para chegar a novas constatações.

A avaliação do método de reações isodésmicas também deve ser estudado em outros sistemas para que se esclareca a utilidade e as limitações da técnica.

Estas são algumas possibilidades, as mais evidentes de estudos que poderiam ser feitos para continuar o estudo deste tipo de sistema e dos métodos de cálculo mais adequados para modelá-los. 


\section{Referências Bibliográficas}

Albrecht, W. Justus Liebigs Ann. Chem. 1906, 348, 31.

Alder, K. ; Stein, Justus Liebigs Ann. Chem. 1953, 501, 247.

Arbuzov, B. A. ; Vulfson, S. G. ; Karaseva, A. N. ; Bikbulatova, G. Sh. ; Vereshchagin, A. N. Izv. Akad. Nauk SSSR, Ser.

Khim. 1976, 1780.

Barltrop, J. A. ; Giles, D. J. Chem. Soc. C 1969, 105.

Becke, A. D. Phys. Rev 1988, 38, 3098.

Becker, D. e Cohen-Arazi, Y. J. Am. Chem. Soc. 1996, 118, 8278.

Benson, S. W. Thermodinamical Kinetics, $2^{\mathrm{a}}$ edição, Wiley, Nova York, 1976.

Bernardi et al. J. Am. Chem. Soc. 1995, 117, 10531.

Bernardi, F.et al., J. Mol. Struct.(Theochem) 1995, 357, 33.

Branchadell, V. et al. J. Am. Chem. Soc. 1997, 119, 9992.

Bruce, J. M. ; Al-Hamdany, R. ; Heatley, F. ; Khalafy, J. J. Chem. Soc Perkin Trans. II 1985, 1395.

Büchi, G. ; Burgess, E. M. J. Am Chem. Soc. 1960, 82, 4333.

Büchi, G. ; Goldman, I. M. J. Am. Chem. Soc. 1957, 79, 4741.

Burke, L. A. et al., Bull. Sac. Chim. Belg. 1979, 88, 379.

Cadd, D. H. et al. Magn. Reson. Chem. 1993, 31, 801.

Carrol, F. A. Perspectives on Structure and Mechanism in Organic Chemistry Brooks/Cole Publishing Company, 1998.

Chambers, C. C.; Cramer C. J.; Truhlar, D. G. J. Phys. Chem. 1996, 100, 16385.

Chow, T. J.; Wu, T-K. Tetrahedron Lett 1989, 30, 1279.

Christiansen, O. et. al. Chern. Phys. Lett. 1996, 261, 369.

Comission on Physical Organic Chemistry, IUPAC Pure Appl. Chem. 1994, 66,

Cookson, R. C. ; Crundwell, E. ; Hill, R. R. ; Hudec, J. J. Chem. Soc. 1964, 3063.

Cookson, R. C. ; Crundwell, E. ; Hudec, J. Chem. and Ind. 1958, 1002.

Cookson, R. C. ; Hill, R. R.). Chem. Soc. 1963, 2023

Coolidge, A. B. S.; Coolidge, M. S. J. Am. Chem. Soc. 1927, 49, 100.

Cossio, F. P. et al. J. Am. Chem. Soc. 1995, 117, 12306.

Cremer, D. ; He, Z. J. Phys. Chem. 1996, 100, 6173.

Curtiss, L. A. et al. J. Chem. Phys. 1998, 108, 692.

Dewar, M. J. S.et al. J. Am. Chem. Soc. 1986, 108, 5771.

Dewar, M. J. S. et al. J. Am. Chem. Soc. 1974, 96, 5246.

Dewar, M. J. S. J. Am. Chem. Soc. 1984, 106, 209.

Diels, K. ; Blom ; Koll Justus Liebigs Ann. Chern. 1925, 443, 247.

Diels, O. ; Alder, K. Ber., 1929, 62, 2362.

Diels, O. ; Alder, K. Justus Liebigs Ann. Chem. 1928, 460, 98.

Dilling, W. L. Chem. Rev. 1966, 373.

Domingo, L. R. et al. J. Org. Chem. 1999, 64, 3026.

Durán, M. et al., J. Chem. Soc. Perkin Trans. 2 1982, 681. 
Eaton, P. E.; Cole, T. W., Jr. J. Am Chem. Soc. 1964, 86, 962, 3157.

Essefar et al. J. Chem. Soc. Perkin Trans. 2 1988, 143.

Evans, M. G.; Polanyi, M. Trans. Far. Soc, 1938, 34, 11.

Evans, M. G. et al. Trans. Far. Soc. 1938, 34, 614.

Evans, M. G. et al. Trans. Far. Soc. 1939, 35, 824.

Filipescu, N. ; Menten, J. M. J. Chem. Soc. B 1969, 617.

Fleming, I. Frontiers Orbitals and Organic Chemical Reactions 1976, J. Wiley and Sons.

Foresman, J. B. ; Frisch, Æ. Exploring Chemistry with Eletronic Structure Methods, Gaussian Inc., 1996.

Hastings, D. J.; A. C. Weedon Can. J. Chem. 1991, 69, 1171.

Hehre, W. J.et al. Ab initio Molecular Orbital Theory, John Wiley and Sons, 1986.

Hehre, W. J.; Lou, L. A Guide to Density Functional Calculations in Spartan, Wavefunction, Inc., 1997.

Hehre, W. J.et al. A Brief Guide to Molecular Mechanics and Quantum Chemical Calculations, Wavefunction, Inc., 1998.

Hinchliffe, A. Computational Quantum Chemistry, John Wiley and Sons, 1989.

Hinchliffe, A. Modelling Molecular Structures, John Wiley and Sons, 1989.

Hoffmann, R. Acc. Chem. Res. 1971, 4, 1.

Hohenberg, P; Kohn, W.Phys. Rev. 1964, 136, B864.

Houk, K. N. et al. Acc. Chem. Res. 1995, $28,81$.

Houk, K. N. et al., J. Am. Chem. Soc. 1998, 120, 12303.

Houk, K. N. et al., J. Chem. Soc. Faraday Trans. 1994, 90, 1599.

Huisgen, R. Pure Appl. Chem. 1980, 52, 2283.

Ibrahim, M. R. J. Phys. Org. Chem. 1990, 3, 126-134 e 443-448.

Jensen, F. Introduction to Computational Chemistry, John Wiley and Sons, 1999.

Jones, G., II et al., J. Photochem 1976, 5, 341.

Jorgensen, W. L. ; Lim, D. J. Phys. Chem. 1996, 100, 17490.

Jug, K. et al., Theor. Chim. Acta 1979, 52, 19.

Karadakov, P. B. et al. J. Am. Chem. Soc. 1998, 120, 3975.

Kroto, H. W.; Heath, J. R.; O'Brien, S. C.; Curl, R. F.; Smalley, R. E. Nature 1985, 318, 162.

Lazare, S. ; de Mayo, P. e Ware, W. R. Photochem. Photobiol. 1981, 34, 187.

Le Févre, C. G. ; Le Févre, R. J. W. J. Chem. Soc. 1935, 1696.

Lee, C.; Yang, W.; Parr, R. G. Phys. Rev. B 1988, 37, 785.

Marchand, A. P. et al. J. Am. Chem. Soc. 1987, 109, 7095.

Marchand, A. P. Aldrichim. Acta 1995, 95.

Maugh, T. H., II Science 1984, 223, 1162.

Mclver, J. W., Jr. Acc. Chem. Res. 1974, 7, 72.

Mehta, G. ; Reddy, A. V. ; Srikrishna, A. Terahedron Lett., 1979, 4863.

Mehta, G. ; Reddy, A. V. J. Chem. Soc. Chem. Commun. 1981, 756.

Mehta, G.; Reddy, D. S.; Murthy, A. N. J. Chem. Soc. Chem. Commun. 1983, 824.

Mehta, G. ; Murthy, A. N J. Chem. Soc. Chem. Commun. 1984, 1058.

Mehta, G. ; Reddy, D. S. ; Reddy, A. V. Tetrahedron Lett. 1984, 25, 2275. 
Møller; C. ; Plesset, M. S. Phys. Rev. 1934, 46, 618.

Montgomery Jr, J. A.et al. J. Chem. Phys. 1998, 108, 6505

Morrison, R. T. ; Boyd, R. N. Organic Chemistry, $6^{a}$ edição, Prentice Hall International, London, 1992.

Nyden, M. R. ; Petersson, G. A. J. Chem. Phys. 1981, 75, 1843.

Okamoto, Y.; Senokuchi, K.; Kanematsu, K. Chem. Pharm. Bull. 1985, 33, 3074.

Perdew, J. P. Phys. Rev. B 1986, 33, 8822

Pople, J. A.; Head-Gordon, M.; Raghavachari, K. J. Chem. Phys. 1987, 87, 5968.

Prinzbach et al. Nature, 2000, 407, 60.

Ristic, G. S.; Marinkovic, M. D.; Comor, J. J.; Nicolic, R. M.J. Mol. Str. 1992, 267, 7.

Ruiz-Lopez, M. F.et al., J. Mol. Struct.(Theochem) 1993, 287, 193.

Rzepa, H. S. ; Yi, M. Y. J. Chem. Soc. Perkin Trans. 2 1991, 531.

Rzepa, H. S. et al., J. Chem. Soc. Perkin Trans. $21991,939$.

Rzepa, H. S. et al., J. Chem. Soc. Perkin Trans. 21993, 1499

Rzepa, H.S. et al., J. Chem. Soc. Perkin Trans. 21998, 2695.

Rzepa, H.S. et al., J. Chem. Soc. Perkin Trans. 21998,857

Scharf, H. D.; Fleischauer, J.; Leissmann, H.; Ressler, I. ; Schleker, W. ; Weitz, R. Angewv. Chem. Int. Ed., 1979, 652.

Shavitt, I. Isr. J. Chem. 1993, 33, 357.

Simons, J. J. Phys. Chem. 1991, 95, 1017.

Simons, J.; Nichols, J. Quantum Mechanics in Chemistry, Oxford University Press, 1997.

Slater, J. C. Quantum Theory of Molecules and Solids, vol. 4, McGraw-Hill, 1963.

Stewart, J. P. J. MOPAC 93 Manual, Revision number 2, Fujitsu Limited, 1994.

Szabo, A.; Ostlund, N. S. Modern Quantum Chemistry, Dover Publications, Inc., 1996.

Truong, T. N. J. Phys. Chem. B 1998, 102, 7877.

Van Orden, A. et al. Chem. Rev. 1998, 98, 2313.

Warrener, R. N. ; McCay; I. W. ; Paddon-Row, M. N. Aust. J. Chem., 1977, 30, 2189.

Wiest, O. ; Houk, K. N. Top. Curr. Chem. 1996, 183, 1.

Wiest, O. ; Montiel, D. C. ; Houk, K. N. J. Phys. Chem. 1997, 101, 8378.

Wladislaw, B. ; Marzoratti, L. ; Arruda Campos, I. P. ; Viertler, H. J. Chem. Soc. Perkin Trans. 21992, 475. .

Woodward, R. B. ; Hoffmann, R. Angew. Chem. Int. Ed. Engl. 1969, 8, 781.

Yamamoto, N.; Vreven, T.; Robb, M. A.; Frisch, M. J.; Schlegel, H. B. Chem, Phys. Lett. 1996, 250, 373.

Yates, P.; Switlak, K. Can. J. Chem. 1990, 68, 1894.

Zewail, A. H. et al., Science 1994, 266, 1359. 